\title{
Visual Experience Facilitates BDNF-Dependent Adaptive Recruitment of New Neurons in the Postembryonic Optic Tectum
}

\author{
Zachary J. Hall and Vincent Tropepe \\ Department of Cell and Systems Biology, University of Toronto, Toronto, Ontario M5S 3G5, Canada
}

Postembryonic brain development is sensitive to environmental input and sensory experience, but the mechanisms underlying healthy adaptive brain growth are poorly understood. Here, we tested the importance of visual experience on larval zebrafish (Danio rerio) postembryonic development of the optic tectum (OT), a midbrain structure involved in visually guided behavior. We first characterized postembryonic neurogenic growth in OT, in which new neurons are generated along the caudal tectal surface and contribute appositionally to anatomical growth. Restricting visual experience during development by rearing larvae in dim light impaired OT anatomical and neurogenic growth, specifically by reducing the survival of new neurons in the medial periventricular gray zone. Neuronal survival in the OT was reduced only when visual experience was restricted for the first $5 \mathrm{~d}$ following new neuron generation, suggesting that tectal neurons exhibit an early sensitive period in which visual experience protects these cells from subsequent neuronal loss. The effect of dim rearing on neuronal survival was mimicked by treatment with an NMDA receptor antagonist early, but not later, in a new neuron's life. Both dim rearing and antagonist treatment reduced $\mathrm{BDNF}$ production in the $\mathrm{OT}$, and supplementing larvae with exogenous $\mathrm{BDNF}$ during dim rearing prevented neuronal loss, suggesting that visual experience protects new tectal neurons through neural activity-dependent BDNF expression. Collectively, we present evidence for a sensitive period of neurogenic adaptive growth in the larval zebrafish OT that relies on visual experience-dependent mechanisms.

Key words: BDNF; glutamate; neurogenesis; optic tectum; visual experience; zebrafish

Significance Statement

Early brain development is shaped by environmental factors via sensory input; however, this form of experience-dependent neuroplasticity is traditionally studied as structural and functional changes within preexisting neurons. Here, we found that restricting visual experience affects development of the larval zebrafish optic tectum, a midbrain structure involved in visually guided behavior, by limiting the survival of newly generated neurons. We found that new tectal neurons exhibit a sensitive period soon after cell birth in which adequate visual experience, likely mediated by neuronal activity driving BDNF production within the tectum, would protect them from subsequent neuronal loss over the following week. Collectively, we present evidence for neurogenic adaptive tectal growth under different environmental lighting conditions.

\section{Introduction}

Postembryonic brain development encapsulates a period of growth in which neural circuits become sufficiently developed to

Received July 11, 2017; revised Jan. 8, 2018; accepted Jan. 15, 2018.

Author contributions:Z.J.H. and V.T. designed research;Z.J.H. performed research;Z.J.H. and V.T. analyzed data; Z.J.H. and V.T. wrote the paper.

This work was supported by the Natural Sciences and Engineering Research Council of Canada Grant PDF4540192014 to ZJH and Discovery Grant RGPIN-2016-06325 to VT. We thank Dr. Chi-Bin Chien, Dr. Jennifer Mitchell, and Dr. Melanie Woodin for sharing reagents and equipement. We thank Dr. Steven Deimling and Dr. Monica Dixon for experimental assistance and Henry Hong for imaging assistance.

The authors declare no competing financial interests.

Correspondence should be addressed to either Dr. Zachary J. Hall or Dr. Vincent Tropepe, Department of Cell and Systems Biology, University of Toronto, 25 Harbord Street, Toronto, Ontario M5S 3G5, Canada, E-mail: zach.hall@utoronto.ca or v.tropepe@utoronto.ca. process incoming sensory input from the environment while levels of synaptic plasticity and neurogenesis remain elevated. Accordingly, many changes in brain structure and function early in postembryonic life are guided by sensory experience, such as the development of ocular dominance (Hubel and Wiesel, 1970), maintenance of visual orientation selectivity in primary visual cortex (Blakemore and Cooper, 1970; Stryker et al., 1978), crossmodality in sensory cortices (Sadato et al., 2002), language acquisition, and motor learning (White et al., 2013). By enabling neurodevelopment to be guided by sensory stimuli, the brain exhibits a form of developmental plasticity, adaptively growing to 
process the stimuli present in the rearing environment (Gilbert and Epel, 2009).

Previous work identifying the cellular mechanisms underlying experience-dependent adaptive brain growth has largely focused on changes in neuronal arborization (Hensch, 2005) and white matter organization (Steele et al., 2013). Few studies have investigated the role neurogenesis may play in adaptive brain growth, presumably because neurogenesis is historically considered a predominantly embryonic event, with only low levels of neurogenesis persisting in specific niches throughout life. However, accumulating evidence suggests that neurogenic growth in the mammalian brain extends into postembryonic development (Feliciano et al., 2015), produces unique neurogenic contributions to brain growth (Wei et al., 2011), and is regulated by sensory experience (Najbauer and Leon, 1995). Thus, postembryonic neurogenesis may, in part, mediate sensory experiencedependent adaptive brain growth.

Here, we investigated the role postembryonic neurogenesis may play in the adaptive growth of the optic tectum (OT) under different visual environments in larval zebrafish. The OT is a midbrain structure involved in many visually guided behaviors and the primary target of visual afferents in the zebrafish brain (Nevin et al., 2010). In teleosts, the OT exhibits constitutive neurogenesis, generating and incorporating new neurons throughout life (Lindsey and Tropepe, 2006; Kaslin et al., 2008; Lindsey et al., 2014). Specifically, new tectal neurons are generated in a neurogenic niche located along the dorsal brain surface in the celldense, ventral layer of the OT called the periventricular gray zone (PGZ) (for review, see Cerveny et al., 2012). Dambroise et al. (2017) recently identified the active stem cells in the teleost tectal niche as neuroepithelial-type cells and not radial glia, a stem cell phenotype found in other teleost neurogenic niches. These neuroepithelial-type stem cells are proposed to grow the tectum appositionally by generating newer cohorts of neurons on top of older cohorts (Ito et al., 2010). Previous work reports that early OT functional development appears to progress largely independent of visual experience: OT neurons develop functional traits, including retinotopy, receptive fields, and directional selectivity even when larvae are reared in the dark for as late as $7 \mathrm{~d}$ postfertilization (dpf) (Niell and Smith, 2005; Lowe et al., 2013). This development is guided by experience-independent, spontaneous activity in the retina and OT (Romano et al., 2015; Pietri et al., 2017). A limitation of these studies is their focus on the first few days of postembryonic development, despite the fact that the brain continues to exhibit tremendous neurogenic growth while tectal-dependent behaviors improve, such as visually guided prey capture (Westphal et al., 2013) well beyond this period of time. This suggests that new tectal neurons after $7 \mathrm{dpf}$ serve an important function in visual development.

In fish, invasive removal of visual inputs via enucleation or optic nerve crush reduces OT cell proliferation (Stevenson and Yoon, 1978; Raymond et al., 1983), which may lead to underdevelopment of the entire OT structure (Schmatolla and Erdmann, 1973). Testing visual experience-dependent neurogenesis using destructive techniques to remove visual input, however, may be complicated by contemporaneous activation of degenerative, repair or even regeneration processes, such as the activation of otherwise quiescent radial glia stem cells (Kizil et al., 2012). Accordingly, these manipulations may not capture the natural range of visual experiences in which the fish brain evolved. Engeszer et al. (2007) found that, in wild zebrafish populations, nesting sites exhibit tremendous variation in visibility, ranging from clarity to extreme turbidity, suggesting the ambient intensity of light during postembryonic development may vary greatly between differ- ent zebrafish clutches. Here, we asked whether the intensity of light during rearing impacts postembryonic OT neurogenesis and subsequent tectal growth. We hypothesized that new neurons would be generated and incorporated in OT via visual activity-dependent mechanisms. Thompson and Scott (2016) found that reducing visual stimulus intensity reduces the associated acute neural response in the tectum. Although this study did not modulate environmental light intensity, if rearing larvae in dim light reduces the intensity of all visual stimuli, we may expect that larvae reared in dim light exhibit reduced visual experiencedependent activity in OT and, as a consequence, reduced new neuron recruitment.

\section{Materials and Methods}

Animals. Zebrafish strains used to in this study include wild-type $\mathrm{AB}$ (ZIRC) and the transgenic strains $T g(d l \times 5 / 6: g f p)$ (generously provided by Dr. Marc Ekker), Tg(her4.1mCherryT2ACreERT2) (rederived transgenic line from a DNA construct generously provided by Dr. Michael Brand), and $\operatorname{Tg}($ isl $2 b: m g f p)$ bred to a nacre background (generously provided by Dr. Chi-Bin Chien and Dr. Tod Thiele, respectively). In all experiments, embryos were collected and moved to Petri dishes containing system water held in a $28^{\circ} \mathrm{C}$ dark incubator. On $1 \mathrm{dpf}$, larvae were screened for fluorescence; then the water containing larvae was bleached and rinsed with fresh system water, and larvae were dechorionated and moved into fresh system water. For work characterizing normal tectal development, $4-5$ dpf larvae were moved into acrylic plastic fish tanks $(n=15-20)$ in our fish facility held at $28^{\circ} \mathrm{C}$ on a $14 \mathrm{~h} \mathrm{light} / 10 \mathrm{~h}$ dark cycle and fed size 0 food (Gemma Micro, Skretting) twice daily. Alternatively, all light rearing manipulations were performed in a separate experimental room held at similar conditions to the fish facility, but without light. Tanks (without lids) were illuminated from above by optic light sources and bulbs ( $21 \mathrm{~V}$; $150 \mathrm{~W}$; Ushio Halogen projector lamp) assumed to provide near full spectrum light (as in Lindsey et al., 2014) on a 14:10 light/dark cycle. For all experiments, half of the system water in each tank was replaced twice daily. It was not possible to identify the sex of zebrafish larvae at this age. All animal experiments were performed with the approval of the University of Toronto Animal Care Committee in accordance with Canadian Council for Animal Care guidelines.

Tectal and retinal neuroanatomy. To characterize gross anatomical tectal growth, we estimated the volume of the tectal neuropil. In Hoechststained coronal sections, we measured cross-sectional neuropil area in $20 \mu \mathrm{m}$ serial sections in FIJI (ImageJ) and calculated the volume between sampled sections using the formula for a frustrum (truncated cone; intersection interval $=20 \mu \mathrm{m}$ ) as follows:

$$
\begin{gathered}
\text { volume between sections }\left(\mu m^{3}\right)=\frac{20}{3}\left(a_{1}+\sqrt{a_{1} a_{2}}+a_{2}\right) \\
a_{1}=\text { area of first section }\left(\mu m^{2}\right) \\
a_{2}=\text { area of second section }\left(\mu m^{2}\right)
\end{gathered}
$$

Consecutive frustra were added to obtain a whole neuropil volume. In $\operatorname{Tg}($ isl2b:mgfp $)$ larval brains, $\mathrm{GFP}^{+}$retinotectal axons are visible as an arborization field in the dorsal tectal neuropil. In later experiments, we estimated the relative volume of this $\mathrm{GFP}^{+}$arborization field using a frustrum calculation and divided it by the estimated neuropil volume. To estimate neuropil cell density, we counted the number of Hoechst ${ }^{+}$cells in serial sections using IMARIS (Bitplane) throughout the neuropil and divided this cell count by the neuropil volume. Both neuropil volume and cell density were averaged across hemispheres before statistical analysis.

In addition to estimating relative volume of the $\mathrm{GFP}^{+}$retinotectal arborization field in the tectal neuropil, we also performed whole-mount imaging to sample absolute $\mathrm{GFP}^{+}$retinotectal arborization field volume in $T g$ (isl2b:mgfp) larvae crossed into a nacre background, so that skin pigmentation would not interfere with imaging. On 5, 10, and $16 \mathrm{dpf}$, larvae were anesthetized and mounted in a plastic dish with a microscope cover base on a Leica TCS SP8 point scan confocal microscope. Larvae 
were positioned such that an entire $\mathrm{GFP}^{+}$retinotectal arborization could be captured as a $z$-stack. Following the first round of imaging on $5 \mathrm{dpf}$, larvae were rinsed and moved into individual wells in 6-well plates in system water that was changed twice daily, enabling repeated scans of individual larvae at 10 and $16 \mathrm{dpf}$.

To sample the density of retinal ganglion cells along the ganglion cell layer, we used a single $20-\mu \mathrm{m}$-thick coronal section of the retina in $\operatorname{Tg}($ isl $2 b: m g f p)$ larvae. All sections used were located within 1 section width $(20 \mu \mathrm{m})$ of the coronal section containing the optic nerve. We used IMARIS (Bitplane) to count the number of $\mathrm{GFP}^{+}$retinal ganglion cells and divided this number by the length of the ganglion cell layer in this section to produce an estimate of retinal ganglion cell density.

Sampling cell proliferation. We sampled cell proliferation and neuronal fate by exposing larvae to 5-ethynyl-2'-deoxyuridine (EdU, Invitrogen), a synthetic thymidine analog that incorporates into newly generated cells during DNA synthesis (Salic and Mitchison, 2008). To sample cell proliferation, groups of larvae were moved into Petri dishes containing $5 \mathrm{~mm}$ EdU dissolved in system water for $24 \mathrm{~h}$ from $4-5,9-10$, or $15-16 \mathrm{dpf}$ $(n=20)$, then immediately killed. By immediately killing larvae following EdU exposure, we can estimate the number of new cells generated during EdU exposure. For analyses within individuals (such as testing for a caudal bias in tectal cell proliferation), we sampled proliferation as the proportion of $\mathrm{EdU}^{+}$cells sampled in a section from the total number of $\mathrm{EdU}^{+}$cells sampled throughout the rostrocaudal axis within the same tectum.

Alternatively, for between-groups analysis, we sampled cell proliferation in the medial and lateral neurogenic niches in the caudalmost two consecutive coronal sections of the PGZ containing tectal neuropil. Here, we report cell proliferation measures as the number of EdU ${ }^{+}$cells corrected for the number of Hoechst ${ }^{+}$cells in the medial and lateral neurogenic niche. To achieve Hoechst ${ }^{+}$cell counts, we established anatomical boundaries in coronal sections of both niches using the distribution of $\mathrm{EdU}^{+}$cells, the brain surface, and the adjacent neuropil. The lateral niche was defined as the lateral brain surface (lateral boundary), the ventral surface of the neuropil (as the dorsal boundary), the ventral surface of the OT (as the ventral boundary), and the point at which the OT and torus semicircularis thinned beneath the tectal neuropil (as the medial boundary). The medial niche was defined as the dorsal surface of the OT (dorsal boundary), the midline (medial boundary), the medioventral surface of the tectal neuropil (lateral boundary), and a horizontal line (perpendicular to the midline) connecting the midline and the point at which the ventral boundary of the OT curves laterally away from the midline (ventral boundary). Results reported here were unchanged when tests were repeated using the raw number of EdU ${ }^{+}$cells/section (data not shown), not corrected for Hoechst ${ }^{+}$cell counts.

Sampling new cell phenotypes. To track the displacement of new PGZ neurons, we exposed $5 \mathrm{dpf}$ larvae to $5 \mathrm{~mm}$ EdU for $6 \mathrm{~h}$, rinsed, and chased for either 5 or $11 \mathrm{~d}$, corresponding to ages 10 and $16 \mathrm{dpf}$, respectively. We quantified the displacement of chased cells from the brain surface by sampling the proportion of EdU ${ }^{+}$cells within the coronal section (standardized as the caudalmost coronal section containing the tectal neuropil) that fell within $14 \mu \mathrm{m}$ distance bins starting at the brain surface and progressing inward.

Neuronal phenotyping was performed on larvae exposed to $5 \mathrm{~mm}$ EdU for $2 \mathrm{~h}$ on $4 \mathrm{dpf}$ and killed on 5, 10, or $16 \mathrm{dpf}$. Phenotypes were sampled and are presented as the proportion of the $\mathrm{EdU}^{+}$cell cohort in the medial and lateral PGZ that coexpress a neuronal phenotype marker.

To sample neuronal survival, we sampled the number of EdU ${ }^{+}$cells/ section in the lateral and medial PGZ as above for proliferation in larvae exposed to EdU for $6 \mathrm{~h}$ on $5 \mathrm{dpf}$ and killed on either 10 or $16 \mathrm{dpf}$. EdU counts were averaged across hemispheres and two consecutive sections. To further assess neuronal survival, we sampled the number of cells producing activated caspase-3, a marker of apoptosis, in $16 \mathrm{dpf}$ larvae exposed to EdU on $5 \mathrm{dpf}$. Caspase- 3 counts were performed in the lateral and medial PGZ using standardized boundaries (brain surface, ventral OT boundary, OT neuropil, and, medially, the $\mathrm{EdU}^{+}$cohort of cells born on $5 \mathrm{dpf}$ ) to enable correction for the number of Hoechst ${ }^{+}$cells. As tectal growth is assumed to be appositional, using $\mathrm{EdU}^{+}$cells born on $5 \mathrm{dpf}$ before light treatment as a medial boundary in our counts means our cell sampling would be focusing on cells born exclusively during light treatments.

Glutamate antagonism. We blocked glutamatergic signaling in the larval brain by administering intracerebroventricular (ICV) injections of either APV (\#0106, Tocris Bioscience) or CNQX (\#C239, Sigma-Aldrich, both antagonists were generously provided by Dr. Melanie Woodin), competitive antagonists for NMDA and AMPA/kainate receptors, respectively. All drugs were dissolved in water and then mixed 9:1 drug:Fast Green (Sigma-Aldrich), to confirm administration of the drug during injections visually. Before injections, larvae were individually anesthetized using tricaine and moved into a restraint mold carved out of $2 \%$ agarose and filled with system water placed on a stereoscope (Leica MZ16) stage. Pulled glass needles (World Precision Instruments, TW100F-4) were filled with solutions to be injected and attached to an IM 300 Microinjector (Narishige). Larvae were positioned with the dorsal surface of the head upward, and injections were targeted to the fourth ventricle. Larvae were monitored through the stereoscope during injections: all solutions were administered until Fast Green was visible throughout the ventricular system, at which point larvae were rinsed and moved into a recovery tank filled with fresh system water.

We administered APV and CNQX at $100 \mu \mathrm{M}, 1 \mathrm{~mm}$, and $9 \mathrm{~mm}$ concentrations either early (5 and $8 \mathrm{dpf}$ ) or late (11 and $14 \mathrm{dpf}$ ) in the development of $5 \mathrm{dpf}$-born new neurons; however, we only found that 9 mM APV affected subsequent neuronal survival (see below). Furthermore, we found that both $9 \mathrm{~mm}$ APV and $9 \mathrm{~mm}$ CNQX injections blocked swimming temporarily for at least $1 \mathrm{~h}$ after injection on $5,8,11$, and 14 dpf compared with controls (data not shown), consistent with previous reports of the importance of glutamate in larval locomotion (McDearmid and Drapeau, 2006).

BDNF treatment. We supplemented larvae reared in dim light with exogenous human BDNF (\#B-250, Alomone Labs) dissolved in water and BSA $(0.1 \mathrm{mg} / \mathrm{ml})$. To validate treatment concentrations, we administered ICV injections of BDNF to $5 \mathrm{dpf}$ larvae at one of three concentrations $(1,10$, or $100 \mathrm{ng} / \mathrm{ml})$ or a vehicle control and killed larvae $1 \mathrm{~h}$ later to sample the amount of BDNF histologically in the medial PGZ.

To provide larvae with exogenous BDNF during dim rearing, we injected larvae on 5,7 , and $9 \mathrm{dpf}$ with $100 \mathrm{ng} / \mathrm{ml}$ BDNF or a BSA vehicle control. Unlike glutamate antagonist injections, BDNF and vehicle control injections were all performed in a dark laboratory before sunrise (between 6:00 AM and 8:00 AM) to minimize exposure to bright light in groups subject to dim rearing. Larvae were anesthetized before being moved under the light source of the stereoscope for injections. Recovery tanks were all kept in the dark and only moved back to the light treatment room once all larvae with a group were treated.

Immunohistochemistry. Histological processing followed previously published protocols (Souza et al., 2011; Lindsey et al., 2012). Larvae were sectioned using a freezing cryostat (20 $\mu \mathrm{m}$ sections), thaw-mounted on $\mathrm{Su}$ perfrost Plus slides (Fisher Scientific), and dried for $3 \mathrm{~h}$ in the dark at room temperature. Tissue was rehydrated in $0.2 \%$ Tween 20 in PBS (PBT) for 30 $\mathrm{min}$ at room temperature. Sections to be labeled for Elavl3 expression were incubated with $4 \%$ PFA for $20 \mathrm{~min}$ at room temperature and treated with 50 mM Tris, $\mathrm{pH} 8.0$, for $60 \mathrm{~min}$ at $75^{\circ} \mathrm{C}-80^{\circ} \mathrm{C}$, then rinsed three times with $\mathrm{PBS}$ and once with PBT. All tissue was washed with PBT three times and blocked with $2 \%$ normal goat serum (NGS) in PBT for at least $2 \mathrm{~h}$ at room temperature. Tissue was incubated with the primary antibody in $2 \%$ NGS in PBT at $4^{\circ} \mathrm{C}$. Primary antibodies used in this study (and prior studies including the use of each antibody in zebrafish) included mouse anti-Human Neuronal Protein Elavl3 (also called HuC/D; Invitrogen, A-21271, 1:400) (Souza et al., 2011), rabbit anti-CalbindinD-28k (SWANT CB-38a, 1:600) (Lindsey et al., 2012), rabbit anti-DsRed-Express (used to enhance endogenous mCherry expression in the $\mathrm{Tg}$ (her4.1mCherryT2ACreER ${ }^{T 2}$ ) line; Clontech, 632496, 1:500) (Walker et al., 2013), mouse anti-glutamate decarboxylase, a marker of GABAergic neurons in the zebrafish brain (Sigma-Aldrich, G5163, 1:200) (Saade et al., 2013), mouse cleaved caspase 3, a marker of apoptosis (Cell Signaling Technology, 9661, 1:200) (Ju et al., 2014), rabbit anti-BDNF (Santa Cruz Biotechnology, sc-546, 1:500) (Gatta et al., 2016), and rabbit anti-GFP (Alexa-488 conjugated, Invitrogen, A-21311, 1:1000) (Souza et al., 2011). On the next day, tissue was rinsed three times with PBT before being incubated in a secondary antibody in $2 \%$ NGS in PBT for $1-2 \mathrm{~h}$ at room temper- 
ature. Secondary antibodies used included $\mathrm{Cy} 3$-conjugated goat anti-mouse IgG (Jackson ImmunoResearch Laboratories, 115-165-146, 1:500), Cy3conjugated goat anti-rabbit IgG (Jackson ImmunoResearch Laboratories, 111-165-144, 1:500), and Cy2-conjugated goat anti-rabbit IgG (Jackson ImmunoResearch Laboratories, 111-225-144, 1:500). Tissue was rinsed with PBT three times. To visualize EdU, a Click-iT EdU reaction was performed as per the instructions (Invitrogen Click-iT EdU Imaging Kits, Alexa-647 azide, C10340, Invitrogen). Tissue was then rinsed in PBT, counterstained with Hoechst for $10 \mathrm{~min}$, rinsed with PBS, and coverslipped using 90\% glycerol in PBS. Coverslips were sealed with clear nail polish and stored at $4^{\circ} \mathrm{C}$ until imaging. Images were captured with a Leica SP8 confocal microscope using a $40 \times$ objective as image stacks throughout the focus of sections compared as $z$-stacks with a $z$ sampling distance of $1 \mu \mathrm{m}$.

In situ hybridization. To identify mitotically active regions in the OT, we performed whole-mount in situ hybridization on $5 \mathrm{dpf}$ larvae to visualize expression of $c c n d 1$, a gene encoding cyclinD1, a protein required for progression through the $G_{1}$ phase of mitosis, using a previously published protocol (Deimling et al., 2015) modified for larval zebrafish. Specific modifications included incubating larvae in $5 \mu \mathrm{g} / \mathrm{ml}$ Proteinase K in Tris-buffered saline with $0.1 \%$ Tween 20 (TBST) for 15 min following methanol rehydration on day 1 and rinsing larvae overnight at $4^{\circ} \mathrm{C}$ in TBST on day 3 before visualizing hybridized probe on day 4 . The antisense probe used was ordered from ZIRC (clone cb161; GenBank: CB333814) and has been characterized by Thisse et al. (2001). The staining we observe here matches the patterns reported by Thisse et al. (2001).

Real-time PCR. We tested whether NMDA receptor (NMDAR) antagonism using APV reduced BDNF expression using real-time PCR. After injecting $8 \mathrm{dpf}$ larvae with either $9 \mathrm{~mm}$ APV or a vehicle control, we dissected the brains from 10 larvae from each treatment $6 \mathrm{~h}$ after injection. RNA was extracted from each sample using Trizol (Invitrogen) according to the manufacturer's instructions. RNA concentration was estimated using a Nanodrop ONE (Thermo Scientific), and $300 \mathrm{ng}$ of RNA was used to synthesize cDNA using the Superscript IV FirstStrand Synthesis System (Invitrogen, 18091050) and Oligo dT18 primers (Thermo Scientific, SO131). Real-time PCRs were performed with LightCycler 480 SYBR Green I Master Mix (Roche, 04707516001) in triplicate. Expression levels in real-time reactions for BDNF and $\beta$-actin were sampled using a CFX384 Real-Time System (Bio-Rad Laboratories) and the following primers: $\beta$-actin forward, 5 '-CGAGCAGGAGATGGGAACC$3^{\prime} ; \beta$-actin reverse, $5^{\prime}$-CAACGGAAACGCTCATTGC-3' (McCurley and Callard, 2008); BDNF forward, $5^{\prime}$-ATAGTAACGAACAGGATGG-3'; and BDNF reverse, 5' -GCTCAGTCATGGGAGTCC-3' (De Felice et al., 2014). RNA expression was analyzed using CFX Manager 3.0 (Bio-Rad Laboratories) to obtain BDNF expression values relative to $\beta$-actin expression.

Western blot. To test whether exogenous BDNF was detectable in whole-brain lysates following ICV injections, we performed a Western blot using $5 \mathrm{dpf}$ larvae injected with either $100 \mathrm{ng} / \mathrm{ml}$ recombinant human BDNF protein (\#B-250, Alomone Labs) or a vehicle control. Following injections, we dissected 30 brains from each group into $40 \mu \mathrm{l}$ cold lysis buffer (10 mm Tris- $\mathrm{HCl}, \mathrm{pH} 7.9,420 \mathrm{~mm} \mathrm{NaCl}, 0.1 \%$ NP-40, $1 \%$ protease inhibitor mixture, Sigma-Aldrich, catalog \#P2714). Tissue was homogenized using a pestle for $30 \mathrm{~s}$ on ice, incubated on ice for $10 \mathrm{~min}$, sonicated for $10 \mathrm{~s}$ on ice, incubated again on ice for $30 \mathrm{~min}$, spun at $10,000 \times g$ for $30 \mathrm{~min}$ at $4^{\circ} \mathrm{C}$, and the supernatant was removed and stored at $-20^{\circ} \mathrm{C}$. The concentration of protein was determined using a Bradford protein assay. Equal amounts of lysate samples were incubated at $70^{\circ} \mathrm{C}$ for $10 \mathrm{~min}$, loaded into a NuPAGE $4 \%-12 \%$ Bis-Tris gel (Invitrogen), and electrophoresed. Proteins were blotted from the gel onto a PVDF (BioTrace) membrane. The membrane was blocked with 5\% dried milk in TBS-T (TBS, pH $7.5+0.1 \%$ Tween 20 ) and incubated overnight at $4^{\circ} \mathrm{C}$ with a rabbit anti-BDNF primary antibody (Santa Cruz Biotechnology, sc-546, 1:250) in TBS-T 5\% dried milk block. The membrane was washed with TBS-T and then incubated for $1 \mathrm{~h}$ at room temperature with goat anti-rabbit peroxidase-conjugated secondary antibody in TBS-T (Jackson ImmunoResearch Laboratories, 111-035-045, 1:10,000). The reaction was developed using a chemiluminescent reagent (ECL, GE Healthcare) and imaged using a ChemiDoc gel scanner (Bio-Rad Labo- ratories). BDNF immunolabeling yielded a band of $27-28 \mathrm{kDa}$ corresponding to both endogenous proBDNF previously reported in teleost (Tognoli et al., 2010; D’Angelo et al., 2014; Cacialli et al., 2017) and the recombinant $\mathrm{BDNF}$ injected ( $28 \mathrm{kDa}$, Alomone Labs). After imaging, the blot was stripped and restained using a primary antibody raised against $\beta$-actin (mouse monoclonal, Millipore, MAB1501, 1:10,000) and goat anti-mouse peroxidase-conjugated secondary antibody (Jackson ImmunoResearch Laboratories, 115-035-003, 1:10,000). Labeling for $\beta$-actin produced a band at $42 \mathrm{kDa}$.

Statistical analyses. The specific tests used to analyze each experiment are reported alongside results below. When an ANOVA or two-way ANOVA yielded a significant result, post hoc comparisons were done (Tukey's multiple-comparisons test and Sidak's multiple-comparisons test, respectively). Unless otherwise stated, tests were two-tailed and we considered a $p$ value $<0.05$ as statistically significant.

\section{Results \\ Distinct proliferation zones pattern the growth of the larval OT}

To characterize postembryonic growth of the larval OT, we estimated the change in tectal neuropil volume as a proxy for anatomical growth in OT with increasing age. From 5 to $16 \mathrm{dpf}$, neuropil volume significantly increases $\left(F_{(2,16)}=33.71, p<\right.$ 0.0001 , ANOVA), whereas neuropil cell density does not change, suggesting that anatomical growth in OT is accompanied by the incorporation of new cells (Fig. $1 A-D ; F_{(2,28)}=0.5570 ; p=$ 0.5792, ANOVA).

To identify the sources of new cells contributing to OT growth, we exposed $5 \mathrm{dpf}$ larvae to EdU. Consistent with earlier postembryonic development and adulthood (Ito et al., 2010; Cerveny et al., 2012), new tectal cells are generated along the dorsocaudal surface of the PGZ, which, in coronal sections, appear as a niche on both dorsomedial and ventrolateral sides of the tectal neuropil (Fig. 1E). We also identified a population of radial glia-like neural stem cells along the ventral surface of the PGZ, previously reported to appear mitotically inactive in adult zebrafish (Ito et al., 2010), by the expression of her4.1-dependent mCherry expression in the transgenic line $\mathrm{Tg}$ (her4.1:mCherryT2ACreERT2). Overwhelmingly, her4.1-expressing cells within the OT did not incorporate EdU; however, a small number of her4.1 ${ }^{+}$cells incorporate EdU in the medial neurogenic niche (Fig. 1Ei-Eiii, white arrows). Furthermore, $\mathrm{EdU}^{+}$cells were never observed along the ventral PGZ boundary, within OT. We analyzed the expression of the ccnd1 gene, encoding the cell cycle regulator cyclinD1, as an alternative marker of cell proliferation. Consistent with our EdU analysis, ccnd1 expression is restricted to the lateral and medial neurogenic niches in a pattern that overlaps with EdU labeling in mid-PGZ, where medial and lateral niches are separated by the tectal neuropil, and PGZ caudal to the neuropil, where medial and lateral niches meet on the dorsal surface of OT (Fig. 1F, G). Collectively, our data show that larval OT growth occurs along the medial and lateral, but not ventral, surfaces of the PGZ.

We then followed a cohort of cells labeled with EdU at $5 \mathrm{dpf}$ to characterize how new cells incorporate into the PGZ. Cohorts of new cells born on $5 \mathrm{dpf}$ appear to displace inward from the tectal surface from 5 to $16 \mathrm{dpf}$ (Fig. $1 H-J$; medial niche: $n=3$, Age $\times$ Distance interaction, $F_{(8,20)}=25.78, p<0.0001$, two-way ANOVA; lateral niche: $n=3$, Age $\times$ Distance interaction, $F_{(8,20)}=43.92, p<0.0001$, two-way ANOVA). Previous work has suggested that neurogenic PGZ growth is appositional, in which newer cohorts of cells form on top of older cohorts (Raymond and Easter, 1983). If PGZ growth is appositional, we predicted that the volume of PGZ contained within $\mathrm{EdU}^{+}$cohorts 

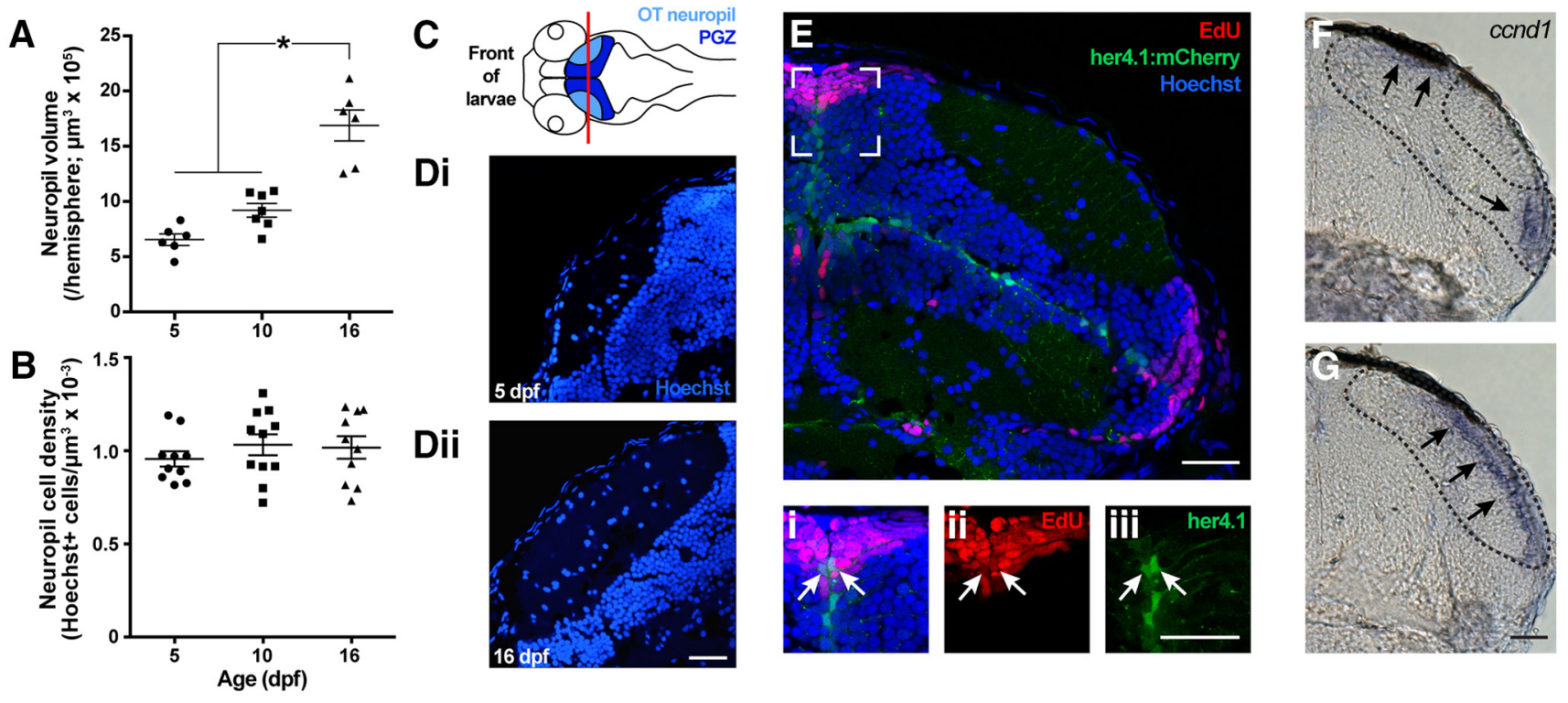
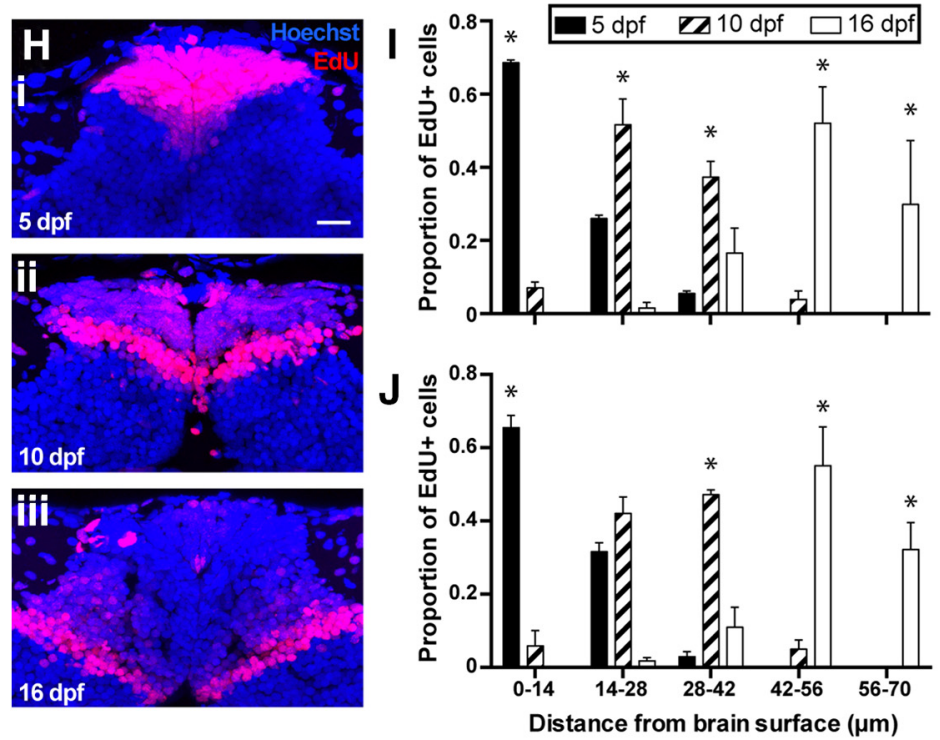
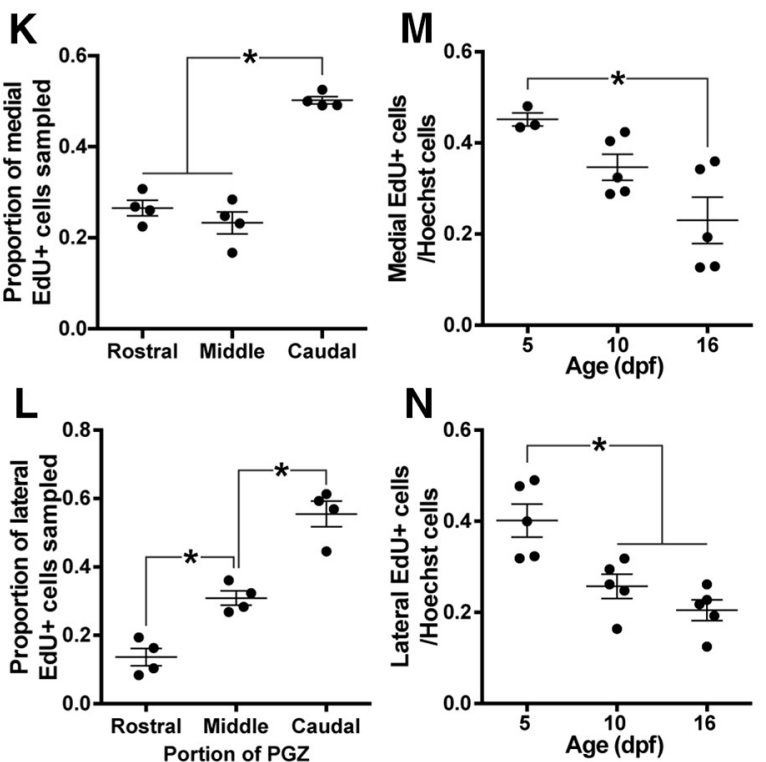

Figure 1. Characterizing normal OT neurogenic growth in 5-16 dpf zebrafish larvae. From 10 to $16 \mathrm{dpf}$, the volume of the tectal neuropil increases $(\boldsymbol{A})$, whereas the Hoechst ${ }^{+}$cell density in the tectal neuropil remains the same $(\boldsymbol{B})$. C, Dorsal, horizontal schematic of a larval brain, indicating locations of the $0 \mathrm{~T}$ neuropil, PGZ, and the coronal plane along which the tectum was sectioned (red line referring to the location of sections in a $5 \mathrm{dpf}$ (Di) and $16 \mathrm{dpf}$ (Dii) larvae below). Scale bar, $20 \mu \mathrm{m}$. New tectal cells are generated in the mediodorsal and ventrolateral PGZ, as visualized by EdU ${ }^{+}$ labeling (E). Scale bar, $30 \mu \mathrm{m}$. A radial glial stem cell population, as visualized by expression of her4. 1:mCherry enhanced using immunohistochemistry with a DsRed antibody that cross-reacts with $\mathrm{mCherry}$, in the $0 \mathrm{~T}$ exists across the ventral and medial boundaries of PGZ and appear overwhelmingly quiescent, with only few $\mathrm{mCherry}{ }^{+}$cells incorporating EdU in the medial neurogenic niche (Ei-Eiii). Scale bar, $30 \mu \mathrm{m}$. Proliferative activity in the $0 \mathrm{~T}$ according to expression of ccnd1 concurs with our EdU ${ }^{+}$data, in that proliferation is limited to medial and lateral niche flanking the tectal neuropil (F) that meet dorsally in the caudalmost PGZ, beyond the neuropil (G). Scale bar, $30 \mu \mathrm{m}$. New tectal neurons born on $5 \mathrm{dpf}$ (Hi) appear to displace into the PGZ by 10 (Hii) and $16 \mathrm{dpf}$ (Hiii). Scale bar, $15 \mu \mathrm{m}$. Displacement of EdU ${ }^{+}$cells from 5 to $16 \mathrm{dpf}$ quantified for the medial and lateral niches in I and $J$, respectively. Within the medial and lateral neurogenic niches, most new neurons are generated in the caudal third compared with the middle and rostral third ( $\boldsymbol{K}$ and $\boldsymbol{L}$, respectively). Cell proliferation rates decrease from 5 to $16 \mathrm{dpf}$ in the medial $(\boldsymbol{M})$ and lateral $(\boldsymbol{N})$ neurogenic niches. Lines indicate mean \pm SEM. ${ }^{*} p<0.05$.

from the medial and lateral niches (calculated across four consecutive, coronal sections) would not change from 5 to $16 \mathrm{dpf}$. The PGZ volume contained ventrally within the medial and lateral 5 dpf-born EdU ${ }^{+}$cohorts does not shrink from 5 to $16 \mathrm{dpf}$ ( $5 \mathrm{dpf}$ : $5.83 \pm 0.86 \times 10^{5} \mu \mathrm{m}^{3} ; 10 \mathrm{dpf}: 4.66 \pm 1.06 \times 10^{5} \mu \mathrm{m}^{3} ; 5.30 \pm$ $0.80 \times 10^{5} \mu \mathrm{m}^{3} ; n=4, F_{(2,9)}=1.647, p=0.2458$, ANOVA), confirming that PGZ growth from 5 to $16 \mathrm{dpf}$ is appositional. This PGZ growth also appears to occur primarily in the caudal PGZ: the caudal third of PGZ generates significantly more cells than the middle and rostral third of OT in both the medial
(Fig. $1 K ; n=4, F_{(2.9)}=45.58, p=0.0061$, repeated-measures ANOVA) and lateral (Fig. $1 L ; n=4, F_{(2,9)}=35.39, p=0.0035$, repeated-measures ANOVA) neurogenic niches. Finally, we also found cell proliferation in PGZ decreases significantly in both neurogenic niches (Fig. $1 M, N$; medial niche: $n=3-5, F_{(2,10)}=$ $6.926, p=0.013$, ANOVA; lateral niche: $n=5, F_{(2,12)}=12.22$, $p=0.0013$, ANOVA) from 5 to $16 \mathrm{dpf}$. Thus, although a substantial amount of cells are generated during early larval stages, there is already a clear age-dependent reduction in the relative rate of proliferation from the medial and lateral niches. 

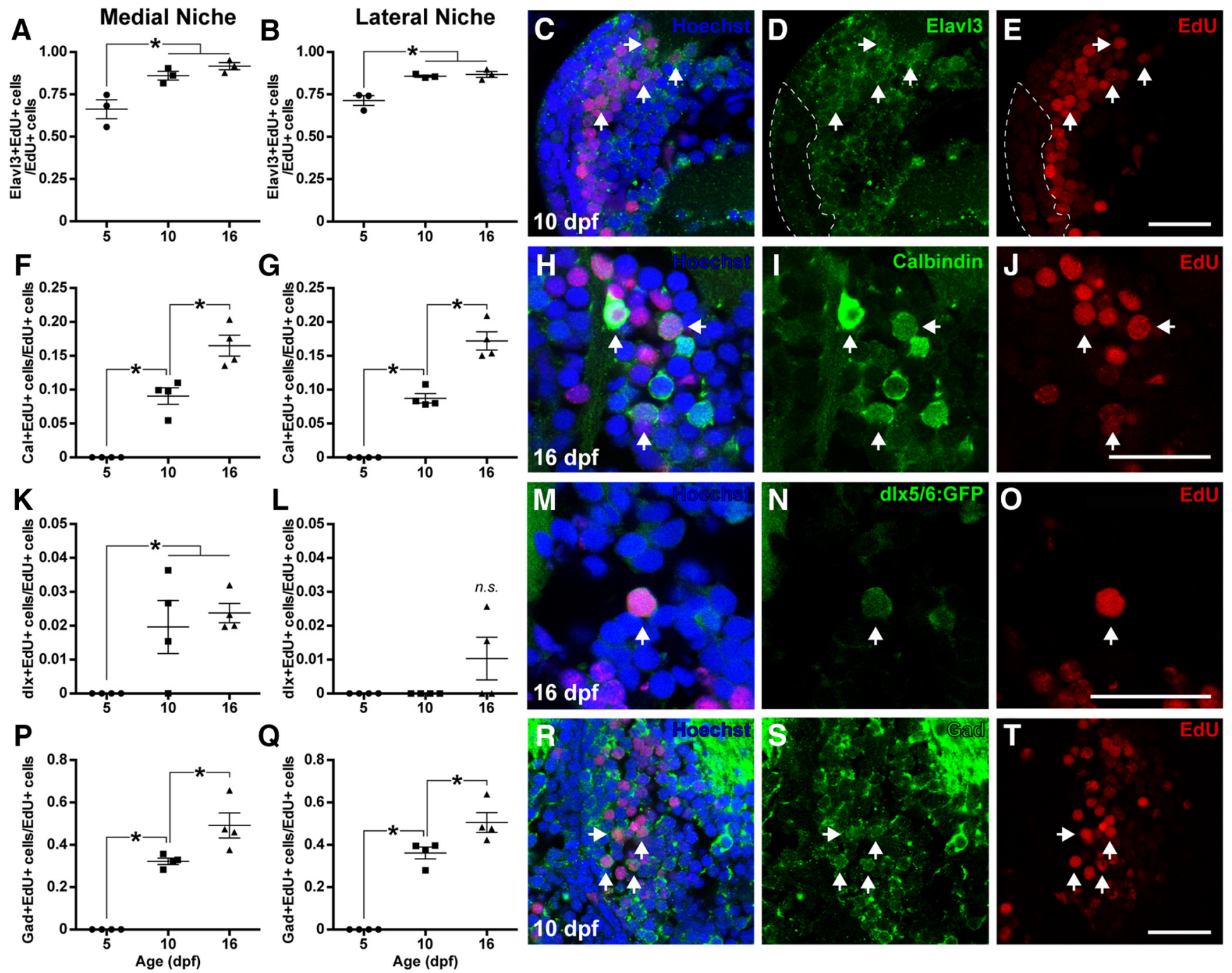

Figure 2. Neuronal phenotypes generated in the $0 \mathrm{~T}$ from 4 to $16 \mathrm{dpf}$. Larvae were exposed to EdU for $2 \mathrm{~h}$ on $4 \mathrm{dpf}$ and killed on 5,10 , or $16 \mathrm{dpf}$. Most new neurons in the $0 \mathrm{~T}$ rapidly adopt a neuronal fate, as assessed by expression of the neuronal marker Elavl3 $(\boldsymbol{A}-\boldsymbol{E})$. Some new neurons born on $4 \mathrm{dpf}$ produce calbindin, a marker of mature neurons by 10 to $16 \mathrm{dpf}(\boldsymbol{F}-\boldsymbol{J})$. Few new neurons in $0 \mathrm{~T}$ express $d / x 5 / 6: m G F P$, a marker typically used to identify a population of predominantly GABAergic neurons in the larval zebrafish brain $(\boldsymbol{K}-\mathbf{0})$. Approximately half of new tectal neurons generated on $4 \mathrm{dpf}$ adopt a GABAergic phenotype, as assessed by expression of Gad by $16 \mathrm{dpf}(\boldsymbol{P}-\boldsymbol{T})$. Scale bars, $20 \mu \mathrm{m}$. White arrows highlight EdU ${ }^{+}$cells also containing neuronal markers. Lines indicate mean \pm SEM. ${ }^{*} p<0.05$.

Collectively, larval OT neurogenic growth from 5 to $16 \mathrm{dpf}$ proceeds appositionally, with new neurons generated along the brain surface and displaced inward by later generations growing atop older ones. Tectal growth is caudally biased and agedependent, suggesting that growth primarily occurs as a caudal expansion of the PGZ and the neuropil, which incorporates new cells in proportion to its coincident neuropil growth.

The majority of newly generated PGZ cells commit to a neuronal identity rapidly but exhibit a delayed expression of mature neuronal markers

Embryonic neurogenesis is marked by relatively distinct epochs of neuronal and glial cell fate determination from early to later stages of development, respectively (for review, see Urbán and Guillemot, 2014). Yet, the fate of newborn cells in adult neurogenic niches is predominantly neuronal (Grandel et al., 2006). We asked whether the "adult-like" pattern of cell fate is established during early postembryonic stages. As early as $24 \mathrm{~h}$ following exposure to EdU, the majority of new cells generated at $4 \mathrm{dpf}$ in the PGZ colabel for the neuronal RNA binding protein Elavl3, and this proportion of Elavl $3^{+} / \mathrm{EdU}^{+}$cells increases to $\sim 85 \%$ of $\mathrm{EdU}^{+}$cell population by $10 \mathrm{dpf}$ (Fig. $2 A-E$; medial niche: $n=3$, $F_{(2,6)}=12.70, p=0.007$, ANOVA; lateral niche: $n=3, F_{(2,6)}=$ $18.45, p=0.0027$, ANOVA). Conversely, almost no new cells express Elavl3 in the tectal neuropil by $5 \mathrm{dpf}$; however, this proportion increases and stabilizes by $10 \mathrm{dpf}(5 \mathrm{dpf}=0.03 \pm 0.02$ Elavl $^{+} \mathrm{EdU}^{+}$cells/EdU ${ }^{+}$cells; $10 \mathrm{dpf}=0.63 \pm 0.01 \mathrm{Elavl}^{+}$ $\mathrm{EdU}^{+}$cells $/ \mathrm{EdU}^{+}$cells; $16 \mathrm{dpf}=0.58 \pm 0.04 \mathrm{Elavl}^{+} \mathrm{EdU}^{+}$ cells/EdU ${ }^{+}$cells; $n=3$ or $4, F_{(2,8)}=150.0, p<0.0001$, ANOVA). The rapid expression of Elavl3 in postmitotic PGZ cells suggests that new PGZ cells commit to a neuronal identity but are not yet fully matured into functional neurons. To test this assumption, we analyzed the expression of calbindin, a marker of a subset of mature neurons (Baimbridge et al., 1992). No newly generated PGZ cells express calbindin within $24 \mathrm{~h}$. By 10-16 dpf, however, the proportion of new PGZ cells expressing calbindin significantly increases to almost 20\% (Fig. $2 F-J$; medial niche: $n=4$, $F_{(2,9)}=52.26, p<0.0001$, ANOVA; lateral niche: $n=4, F_{(2,9)}=$ 97.21, $p<0.0001$, ANOVA). Thus, almost all new PGZ cells 
commit to a neuronal fate rapidly after becoming postmitotic but may require more time to fully mature into neurons.

The stable transgenic line $\operatorname{Tg}(d l x 5 / 6: G F P)$ has been well described in zebrafish larvae previously (Ghanem et al., 2003). This line is characterized by GFP expression in mostly GABAergic neurons in the OT (Robles et al., 2011). Tectal cells generated on $4 \mathrm{dpf}$ rarely express GFP in this transgenic line, even by $16 \mathrm{dpf}$ (Fig. $2 K-O$; medial niche: $n=4, F_{(2,9)}=6.969, p=0.0148$, ANOVA; lateral niche: $n=4, F_{(2,9)}=2.678, p=0.1223$, ANOVA). Because $d l x 5 / 6: G F P$ transgene expression may be limited to a subpopulation of GABAergic neurons predominantly generated before $4 \mathrm{dpf}$, we also directly assessed the GABAergic fate of newly generated PGZ neurons, using the expression of glutamate decarboxylase (Gad), the enzyme required for GABA biosynthesis. Whereas no new cells expressed Gad within $24 \mathrm{~h}$, the proportion of newly generated cells expressing Gad significantly increased to $\sim 50 \%$ in both neurogenic niches by $16 \mathrm{dpf}$ (Fig. $2 P-T$; medial niche: $n=4, F_{(2,9)}=49.85, p<0.0001$, ANOVA; lateral niche: $n=4, F_{(2,9)}=69.30, p<0.0001$, ANOVA). Overall, these data suggest that at least half of the newly generated neurons in the larval PGZ adopt a GABAergic phenotype.

\section{Rearing larvae in a dim environment does not affect body or eye growth}

Given that some features of visual processing associated with OT can develop independently of visual experience (Niell and Smith, 2005; Lowe et al., 2013), we asked whether altering the visual environment after these early stages of development might begin to guide subsequent tectal development. We reared larvae in either standard intensity (100 lux) or dim (5 lux) light and examined tectal neurogenic growth from 5 to $16 \mathrm{dpf}$. We first tested whether rearing larvae in dim light impaired bodily growth. Rearing larvae in dim light does not affect body length on $16 \mathrm{dpf}$ ( 100 lux: $3.94 \pm 0.05 \mathrm{~mm} ; 5$ lux: $3.89 \pm 0.05 \mathrm{~mm} ; n=30, t_{(58)}=$ $0.6742, p=0.5029$, independent $t$ test). We also sampled the effects of dim light on eye development. Dim rearing does not affect lens diameter $(100$ lux $=148.30 \pm 3.59 \mu \mathrm{m} ; 5$ lux $=$ $146.30 \pm 1.67 \mu \mathrm{m} ; n=11, t_{(14)}=0.5046, p=0.6216$, independent $t$ test) or retinal ganglion cell density in the ganglion cell layer of the retina $(100$ lux $=0.70 \pm 0.02$ cells $/ \mu \mathrm{m} ; 5$ lux $=0.70 \pm$ 0.02 cells $/ \mu \mathrm{m} ; n=5-7, t_{(14)}=0.07416, p=0.9423$, independent $t$ test). This suggests that restricting visual experience does not affect development of the body or eyes from 5 to $16 \mathrm{dpf}$.

\section{Restricting visual experience reduces neuropil growth and PGZ neuronal survival without affecting cell proliferation or neuronal phenotypes}

Unlike body or eye development, rearing larvae in dim light impairs neuropil growth in the OT from 10 to $16 \mathrm{dpf}$ (Fig. $3 A-C$; Age $\times$ Light Treatment interaction, $F_{(2,34)}=30.86, p<0.0001$, two-way ANOVA). Interestingly, this difference only manifests at $16 \mathrm{dpf}$, whereas light treatment has no effect on tectal neuropil volume on 5 and $10 \mathrm{dpf}$.

To determine how neurogenic tectal growth could be affected by restricting visual experience, we exposed 5,10 , and $16 \mathrm{dpf}$ larvae reared in standard or dim light to EdU and immediately killed them afterward to ask whether light rearing environment affects the rate of cell proliferation in medial and lateral PGZ. Whereas tectal cell proliferation in both the medial (Fig. 3D; Age effect, $F_{(2,43)}=7.0110, p=0.0023$, two-way ANOVA) and lateral PGZ (Fig. 3E; Age effect, $F_{(2,44)}=15.92, p<0.0001$, two-way
ANOVA) declined from 5 to $10-16 \mathrm{dpf}$, we found no significant effect of either Light Treatment or Age $\times$ Light Treatment interaction on tectal proliferation, indicating that visual environment has little or no influence on progenitor cell proliferation rates at the ages examined.

Aside from cell proliferation, sensory experience may also regulate the recruitment and survival of new neurons following their generation. We exposed $5 \mathrm{dpf}$ larvae to EdU and examined the brain on either 10 or $16 \mathrm{dpf}$ to track whether rearing larvae in a visually restrictive environment affected the survival of new PGZ neurons. Whereas light rearing environment does not affect the survival of $5 \mathrm{dpf}$-born neurons by $10 \mathrm{dpf}$, rearing larvae in dim light significantly reduces the number of these neurons in the medial (Age $\times$ Light Treatment interaction, $F_{(1,24)}=5.512, p=$ 0.0275, two-way ANOVA), but not lateral PGZ (Fig. 3F-I; Age $\times$ Light Treatment interaction, $F_{(1,24)}=0.8796, p=0.3577$, twoway ANOVA) by $16 \mathrm{dpf}$. To further assess whether rearing larvae in dim light reduced cell survival in PGZ, we sampled the number of cells expressing activated caspase-3, a marker of apoptosis in the medial and lateral PGZ on $16 \mathrm{dpf}$ falling between the surface of the brain and the $5 \mathrm{dpf}$-born cohort of $\mathrm{EdU}^{+}$cells now displaced inside of PGZ. Rearing larvae in dim light increases the proportion of cells producing activated caspase- 3 in the medial $\left(n=4, t_{(6)}=3.329, p=0.0158\right.$, independent $t$ test $)$, but not lateral PGZ (Fig. $3 J, K ; n=3$ or $4, t_{(5)}=1.066, p=0.3350$, independent $t$ test). Interestingly, we found no effect of light treatment on activated caspase- 3 expression in cells generated before light treatments, defined by cells falling in between the medial and lateral EdU ${ }^{+}$cohorts in PGZ, because we observed no activated caspase- $3^{+}$cells in this region in all brains sampled (data not shown). Despite reduced neuronal survival in the medial PGZ in larvae reared in dim light, the two most common mature neuronal phenotypes examined here, calbindin and Gad, are produced in similar proportions regardless of rearing light conditions (Calbindin: $100 \mathrm{lux}=0.21 \pm 0.01 \mathrm{Cal}^{+} \mathrm{EdU}^{+}$cells/ EdU cells; 5 lux $=0.22 \pm 0.01 \mathrm{Cal}^{+} \mathrm{EdU}^{+}$cells/EdU cells; $n=4$ or $5, t_{(7)}=0.8445, p=0.4263$; Gad: 100 lux $=0.49 \pm 0.06 \mathrm{Gad}^{+}$ $\mathrm{EdU}^{+}$cells/EdU cells; $5 \mathrm{lux}=0.44 \pm 0.02 \mathrm{Gad}^{+} \mathrm{EdU}^{+}$cells/EdU cells; $n=4, t_{(6)}=0.7924, p=0.4583$, independent $t$ tests), indicating that the neuronal phenotypes generated were not affected by visual experience. Overall, these data suggest that restricted visual experience during postembryonic development impairs the survival of newly generated PGZ neurons and reduces tectal growth. This experience-dependent modulation of neuronal survival manifests between 10 and $16 \mathrm{dpf}$, is primarily localized to the medial OT, and appears to affect different neuronal phenotypes equally.

\section{Restricting visual experience during early, but not late, new neuron development reduces subsequent tectal growth and neuronal survival}

Recent findings indicate that newly generated PGZ neurons undergo functional development and integration into preexisting tectal circuitry over the first $4 \mathrm{~d}$ following birth (Boulanger-Weill et al., 2017). We asked whether restricted visual experience specifically during this period of development (5-10 dpf) or afterward (10-16 dpf) alone could recapitulate our findings on visual experience-dependent tectal growth and neuronal survival above. We repeated our EdU pulse-chase paradigm, to track the survival of 5 dpf-born neurons, but included two new light treatment groups: a late dim group (reared in normal light conditions from 5 to $10 \mathrm{dpf}$ and dim light from 10 to $16 \mathrm{dpf}$ ) and an early dim group (reared in 
A
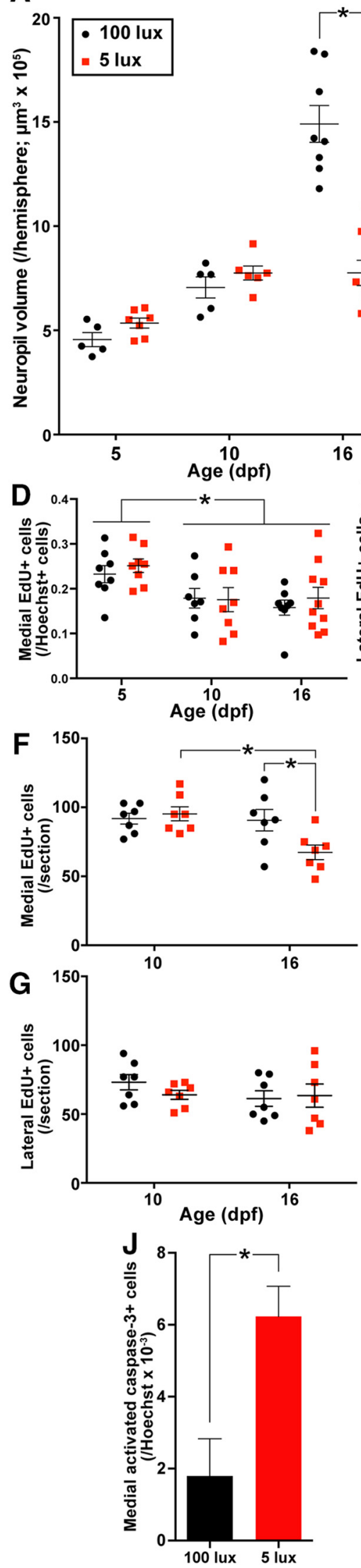

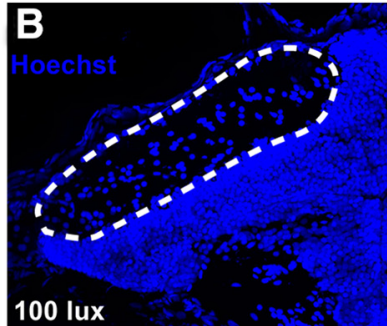

-
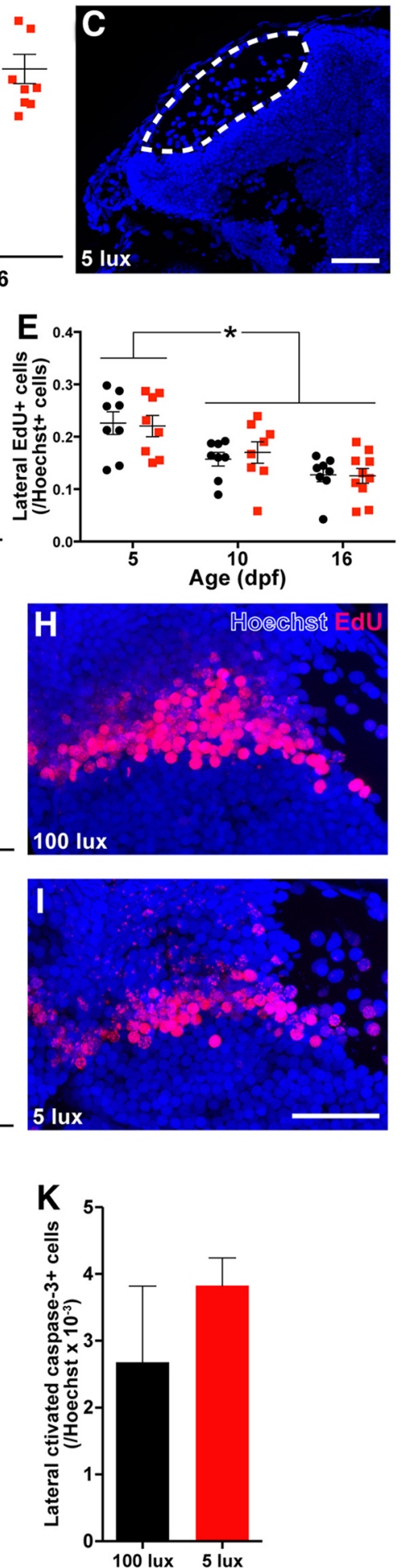

Figure 3. Rearing larvae in $\operatorname{dim}(5 \mathrm{lux}$ ) light reduces tectal neuropil growth on $16 \mathrm{dpf}$ compared with larvae reared in standard (100 lux) light (A-C). Scale bar, $40 \mu \mathrm{m}$. Rearing larvae in dim light did not affect the number of EdU ${ }^{+}$cells generated immediately following a 6 h exposure to EdU in both the medial $(\boldsymbol{D})$ and lateral $(\boldsymbol{E})$ neurogenic niches from 5 to $16 \mathrm{dpf}$. Rearing larvae in dim light

dim light from 5 to $10 \mathrm{dpf}$ and normal light conditions from 10 to $16 \mathrm{dpf}$; Fig. $4 A$ ).

At $16 \mathrm{dpf}$, we found a significant effect of light treatment on neuropil volume: all three groups in which larvae were reared at some point under restricted visual experience exhibited smaller neuropil volume than controls (Fig. $4 B-F ; F_{(3,22)}=$ $10.76, p=0.0001$, ANOVA). Because the tectal neuropil contains the retinotectal arborizations from the eye carrying visual input, we asked whether the reduction in neuropil volume following rearing in dim light might be attributed to a reduction in the volume of neuropil specifically occupied by this retinal input. We captured images of the retinotectal arborizations in $T g$ (isl2b:mgfp) larvae, which express GFP in these projections, crossed into a nacre background on 5, 10, and $16 \mathrm{dpf}$ reared in our four light treatment groups. Light rearing condition did not affect the absolute volume of $\mathrm{GFP}^{+}$retinotectal arborizations in the tectal neuropil from 5 to $16 \mathrm{dpf}$ (Fig. 4G,H; Age $\times$ Treatment interaction: $F_{(6,28)}=1.076, p=0.4003$, twoway ANOVA). We then sectioned larval brains at $16 \mathrm{dpf}$, to estimate the relative volume of the $\mathrm{GFP}^{+}$retinotectal arborization as a proportion of the total tectal neuropil volume. Rearing larvae in a dim light environment from 5 to $10 \mathrm{dpf}$ (early dim and full dim treatments) increases the proportion of tectal neuropil occupied by retinotectal arborizations (Fig. $4 I-M ; F_{(3,23)}=7.372, p=0.0012$, ANOVA). Because absolute retinotectal growth is not affected by light rearing treatment, these findings suggest that rearing larvae from 5 to $10 \mathrm{dpf}$ in lowintensity light reduces other neurite contributions to the neuropil, which may include dendritic arborizations from neurons in $\mathrm{PGZ}$.

Because both early and late rearing in dim light affected neuropil growth, we then asked whether both of these light treatments would reduce new cell survival in the medial PGZ. Rearing larvae in dim light from 5 to $10 \mathrm{dpf}$ (early dim and full dim treatments) reduces the number of 5 dpf-born $\mathrm{EdU}^{+}$cells in the medial PGZ on $16 \mathrm{dpf}$ (Fig. $4 N-R ; F_{(3,19)}=8.577, p=$ 0.0008 , ANOVA). Whereas rearing larvae in dim light at any stage reduces neuropil

reduced the number of EdU ${ }^{+}$cells born on $5 \mathrm{dpf}$ in the medial, but not lateral, neurogenic niche by $16 \mathrm{dpf}(\boldsymbol{F}-\boldsymbol{I})$. Scale bar, 30 $\mu \mathrm{m}$. Rearing larvae in dim light increased the proportion of activated caspase- $3^{+}$cells in the medial, but not lateral, PGZ on 16 $\operatorname{dpf}(\boldsymbol{J}, \boldsymbol{K})$. Lines/bars represent mean \pm SEM. ${ }^{*} p<0.05$. 

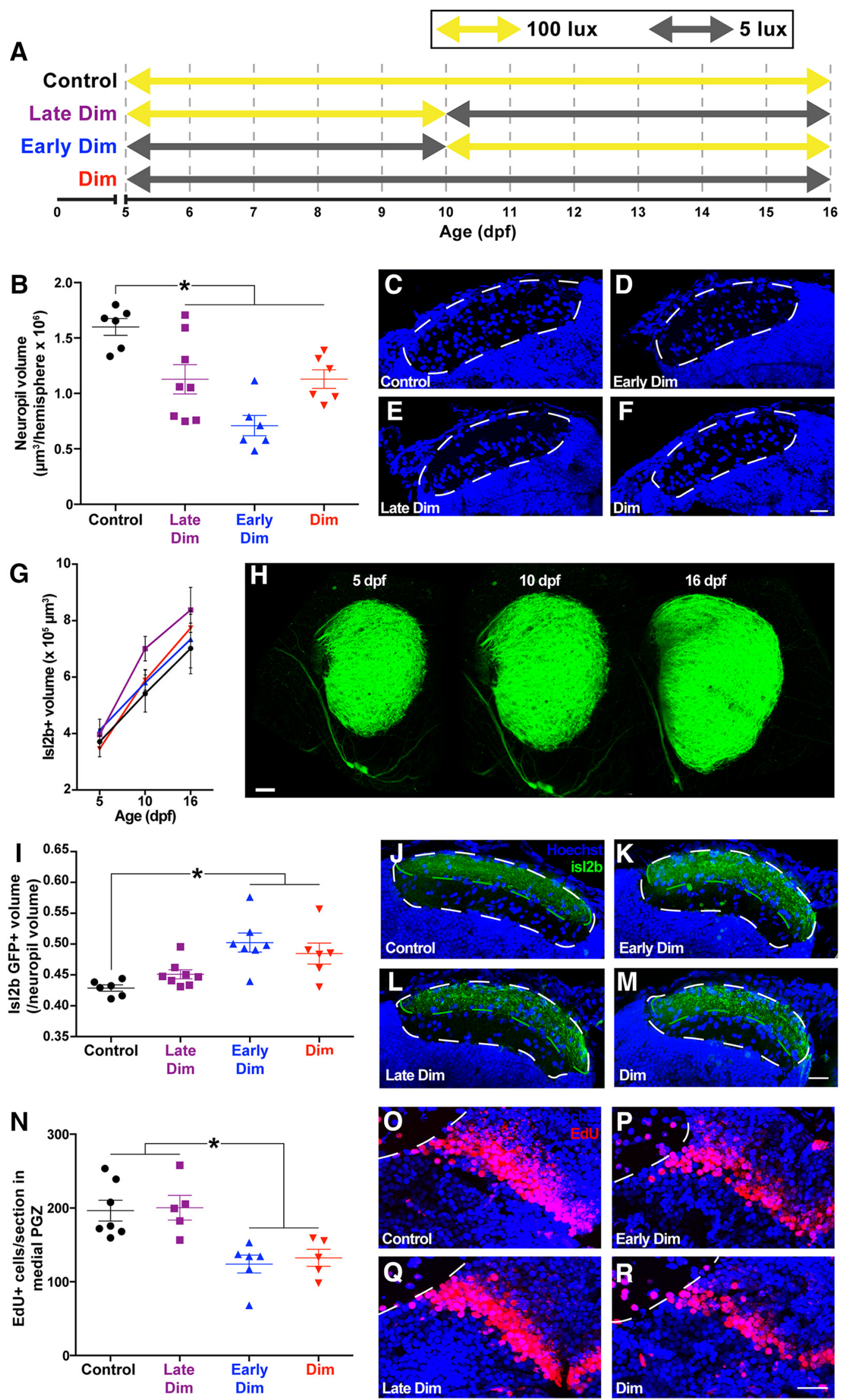

Figure 4. We reared larvae in four lighting conditions to disentangle the effects of restricted visual experience early or late in new neuron development $(\boldsymbol{A})$. Rearing larvae at any point in dim light reduced tectal neuropil volume on $16 \mathrm{dpf}(\boldsymbol{B}-\boldsymbol{F})$. Scale bar, $20 \mu \mathrm{m}$. Micrographs represent coronal sections from the middle of the neuropil. Visual environment during rearing does not affect growth of the volume of retinotectal arborizations, as visualized by GFP ${ }^{+}$expression in $\mathrm{Tg}($ isl $2 \mathrm{~b}$ :mgfp) larvae from 5 to $16 \mathrm{dpf}(\boldsymbol{G}, \boldsymbol{H})$. Scale bar, $30 \mu \mathrm{m}$. Only rearing larvae in dim light from 5 to $10 \mathrm{dpf}$ significantly increased the proportion of the tectal neuropil occupied by retinotectal arborizations $(I-M)$. Scale bar, $20 \mu \mathrm{m}$. Only rearing (Figure legend continues.) 
A

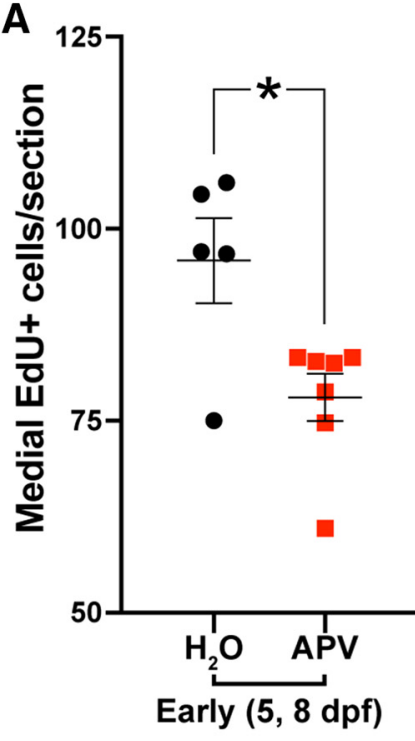

D

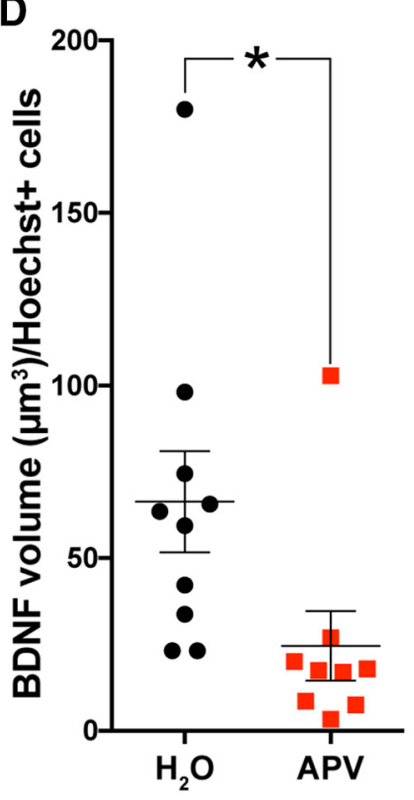

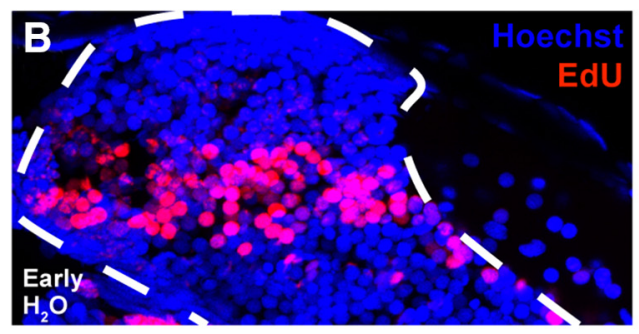

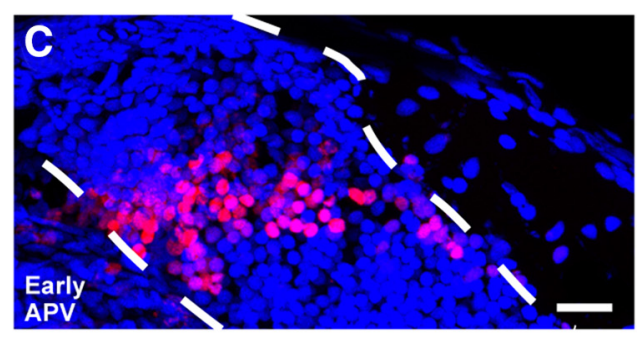

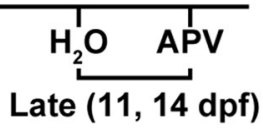
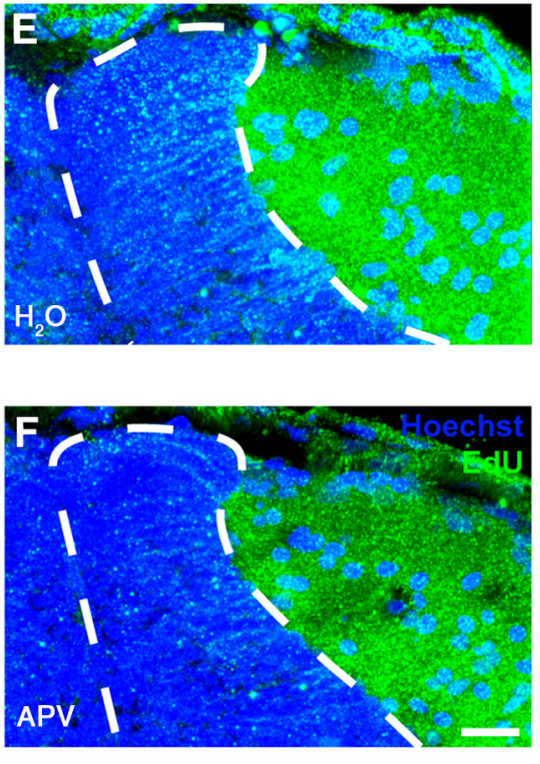

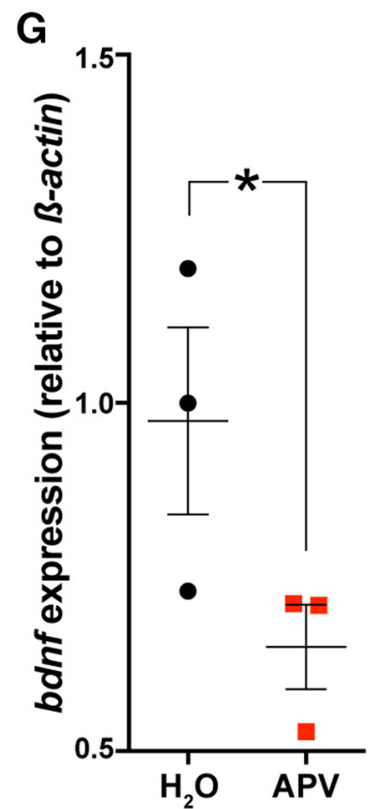

Figure 5. Antagonizing NMDA receptor neurotransmission using ICV injections of 9 mm APV early (5 and $8 \mathrm{dpf}$ ), but not late (11 and $14 \mathrm{dpf}$ ) in a new neuron's development, reduced the survival of $5 \mathrm{dpf}$-born neurons by $16 \mathrm{dpf}(\boldsymbol{A}-\boldsymbol{C})$. Dotted white line indicates the boundaries of PGZ. Scale bar, $15 \mu \mathrm{m}$. Antagonizing NMDA receptor neurotransmission using an ICV injection of 9 mu APV reduces the expression of BDNF protein in the medial PGZ $12 \mathrm{~h}$ after injection in $8 \mathrm{dpflarvae}(\boldsymbol{D}-\boldsymbol{F})$. Dotted white line indicates the boundaries of PGZ. Scale bar, $20 \mu \mathrm{m}$. The expression of BDNF $\mathrm{mRNA}$ in $8 \mathrm{dpf}$ larvae $6 \mathrm{~h}$ after ICV injection with $9 \mathrm{mM} \mathrm{APV}(\boldsymbol{G})$. Lines indicate mean \pm SEM. * $p<0.05$.

volume, only early rearing in dim light also reduces new neuron survival in the PGZ.

Early treatment with APV mimics the effects of dim rearing on neuronal survival

Rearing larvae in dim light likely reduces the amount of retinal input driving activity in OT. Consistent with this assumption, recent work reported that visual stimuli of reduced intensity produce a smaller neural response in PGZ (Thompson and Scott, 2016). Retinal input to the tectum is conveyed entirely by glutamatergic neurotransmission from retinal ganglion cells (Smear et

$\leftarrow$

(Figure legend continued.) larvae in dim light from 5 to $10 \mathrm{dpf}$ reduced neuronal survival in the medial PGZ by $16 \mathrm{dpf}(\boldsymbol{N}-\boldsymbol{R})$. Scale bar, $20 \mu \mathrm{m}$. Lines indicate mean \pm SEM. ${ }^{*} p<0.05$. al., 2007). Accordingly, we predicted that antagonizing glutamatergic signaling early, but not late, after a new cohort of PGZ neurons were born would reduce subsequent neuronal survival in larvae reared under standard lighting conditions, mimicking the effect of early dim rearing.

We antagonized NMDAR and AMPA receptor (AMPAR) glutamatergic neurotransmission using ICV injections of either APV or CNQX, respectively, in larvae reared in standard lighting conditions. We antagonized glutamatergic signaling either early (injections on 5 and $8 \mathrm{dpf}$ ) or late (injections on 11 and $14 \mathrm{dpf}$ ) after the generation of $5 \mathrm{dpf}$ born neurons. We found that early, but not late, treatment with $9 \mathrm{~mm}$ APV reduces the number of EdU ${ }^{+}$ cells in the medial PGZ by $16 \mathrm{dpf}$ (Fig. $5 A-C$; Drug $\times$ Treatment Time interaction, $F_{(1,23)}=6.856, p=0.0154$, two-way ANOVA), whereas lower doses of APV tested had no effect on EdU ${ }^{+}$cells 
counts on $16 \mathrm{dpf}$ (data not shown). Early treatment with $9 \mathrm{~mm}$ APV does not affect the proportion of new neurons that express Gad by $16 \mathrm{dpf}\left(\right.$ Control $=0.4382 \pm 0.03895 \mathrm{Gad}^{+} \mathrm{EdU}^{+} / \mathrm{EdU}^{+}$ cells, APV-treated $=0.4349 \pm 0.01833 \mathrm{Gad}^{+} \mathrm{EdU}^{+} / \mathrm{EdU}^{+}$cells, $n=5, t_{(8)}=0.1712, p=0.8683$, independent $t$ test), similar to larvae reared in dim light as reported above. Furthermore, treatment with $9 \mathrm{~mm}$ APV on $5 \mathrm{dpf}$ does not affect the proportion of $\mathrm{EdU}^{+}$cells in the medial PGZ on $6 \mathrm{dpf}$, a full day following EdU exposure $\left(\right.$ Control $=0.3198 \pm 0.03438 \mathrm{EdU}^{+} / \mathrm{Hoechst}^{+}$cells, APV-treated $=0.2842 \pm 0.3062 \mathrm{EdU}^{+} /$Hoechst $^{+}$cells, $n=6$, $t_{(10)}=0.7727, p=0.4576$, independent $t$ test), suggesting that the effects of APV treatment on tectal neurogenesis are not due to changes in neuroproliferation, but instead neuronal survival, similar to dim rearing treatments. Unlike early treatments with APV, treating larvae with $9 \mathrm{~mm}$ CNQX early or late during new neuron development does not affect the number of $5 \mathrm{dpf}$-born PGZ neurons by $16 \mathrm{dpf}$ (Early Control $=95.29 \pm 13.4 \mathrm{EdU}^{+}$ cells/section, CNQX-treated $=68.71 \pm 10.31 \mathrm{EdU}^{+}$cells $/ \mathrm{sec}$ tion, Late Control $=95.92 \pm 11.49 \mathrm{EdU}^{+}$cells/section, CNQXtreated $=91.67 \pm 12.08 ; n=6 \mathrm{EdU}^{+}$cells/section; Drug $\times$Time interaction $F_{(1,20)}=0.8848, p=0.3581$, two-way ANOVA). Collectively, these results suggest that disrupting neural activity using APV over the first few days following the generation of neurons leads to neuronal loss days later, as observed under dim rearing.

We observed an APV-dependent effect on neuronal survival using the highest treatment concentration tested ( $9 \mathrm{~mm}$ ); however, due to the nature of ICV injections and fluid flow within the ventricles, it is likely that the APV concentration reaching the cells in the OT is $<9 \mathrm{~mm}$. While it may not possible to ascribe the effects of this treatment exclusively to NMDAR antagonism, the role of neural activity-dependent neuronal survival, including its potential mediation through NMDAR, has long been studied (for review, see Zhou et al., 2015) and is consistent with our results. In models in vitro, neural activity drives the production of BDNF, which is proposed to act as a paracrine or autocrine signaling factor that protects neurons from subsequent loss (Marini et al., 1998). We asked whether our ICV injections of $9 \mathrm{~mm} \mathrm{APV}$ could also reduce BDNF as a potential mechanism leading to reduced neuronal survival. We injected a cohort of $8 \mathrm{dpf}$ larvae with $9 \mathrm{~mm}$ APV and collected brains $12 \mathrm{~h}$ later to sample BDNF production histologically. Treating larvae with APV significantly reduces BDNF expression $12 \mathrm{~h}$ later in the medial PGZ (Fig. $5 D-F ; t_{(17)}=2.291, p=0.0350$, independent $t$ test). We then asked whether this localized decrease in BDNF protein production could be detected as a reduction in BDNF mRNA expression preceding the reduction in translation in neurogenic niches. We found that $8 \mathrm{dpf}$ larvae injected with $9 \mathrm{~mm}$ APV exhibit significantly reduced BDNF mRNA expression (relative to $\beta$-actin expression) $6 \mathrm{~h}$ after injection (Fig. $5 G ; t_{(2)}=2.201, p=0.0463$, one-tailed $t$ test). These findings suggest that experiencedependent neural activity increases BDNF transcription and translation within the tectal neurogenic niche.

\section{Early dim rearing reduces tectal BDNF expression, and supplementing $\mathrm{BDNF}$ during dim rearing prevents neuronal loss}

If visual input drives BDNF production to enhance PGZ neuronal survival, then we predicted that rearing larvae in dim light must also reduce BDNF production. We reared larvae in standard or dim light until $10 \mathrm{dpf}$, at which point restricted visual experience has presumably already impacted new neurons; however, these neurons have not died yet (see above). Rearing larvae in dim light reduces BDNF production in the medial PGZ (Fig. $6 A-C$; $t_{(9)}=2.867, p=0.0186$, independent $t$ test).

If restricting visual experience reduces neuronal survival by reducing $\mathrm{BDNF}$ levels in $\mathrm{PGZ}$, then supplementing larvae with exogenous BDNF during early rearing in dim light should protect newly generated neurons from subsequent loss. To determine an appropriate concentration of exogenous BDNF to regulate levels of BDNF in the tectum, we injected $5 \mathrm{dpf}$ larvae with 1,10 , or 100 $\mathrm{ng} / \mathrm{ml}$ of exogenous BDNF or a vehicle control. Injecting $5 \mathrm{dpf}$ larvae with $100 \mathrm{ng} / \mathrm{ml}$ recombinant human BDNF significantly increased the volume of BDNF reactivity in the medial PGZ $1 \mathrm{~h}$ after injection compared with BSA-injected controls (Fig. $6 D$; $\mathrm{K}-\mathrm{W}$ statistic $=11.64, p=0.0087$, Kruskal-Wallis test). This increase in BDNF could also be visualized by Western blot using whole-brain lysates from $5 \mathrm{dpf}$ larvae injected with either BDNF or a vehicle control (Fig. 6E). Accordingly, we opted to treat larvae with $100 \mathrm{ng} / \mathrm{ml}$ exogenous BDNF for subsequent experiments in which BDNF was supplemented in dim-reared larvae.

We reared larvae exposed to EdU on $5 \mathrm{dpf}$ in either standard or dim lighting from 5 to $10 \mathrm{dpf}$. On 5,7 , and $9 \mathrm{dpf}$, half of the larvae reared in dim light were injected with $100 \mathrm{ng} / \mathrm{ml} \mathrm{BDNF}$ and the remaining larvae reared in dim light and larvae reared in standard light were injected with a vehicle control. From $10 \mathrm{dpf}$, all larvae were moved into standard lighting until $16 \mathrm{dpf}$ (treatment summarized in Fig. $6 F$ ). Supplementing larvae reared in dim light with BDNF prevented significant neuronal loss by 16 dpf (Fig. $6 G-J ; F_{(2,40)}=7.87, p=0.0013$, ANOVA).

\section{Discussion}

\section{The neurogenic profile of the larval OT resembles that of adults}

The neurogenic profile of the larval OT, as early as $4 \mathrm{dpf}$, largely resembles that of adult fish with respect to the location of neurogenic niches and the types of cells produced. Cell proliferation is restricted to the medial, dorsal, and lateral PGZ surfaces and exhibits a caudal bias in cell proliferation, similar to OT neurogenesis in other developmental periods (Ito et al., 2010; Cerveny et al., 2012). Conversely, we found that a previously described population of radial-glial-like neural stem cells along the ventral PGZ surface (Ito et al., 2010) expresses the Notch target gene her4. 1 and exhibits almost no proliferative activity, outside of a few dorsomedial cells.

We found that almost all new cells in PGZ adopt a neuronal fate, as sampled by Elavl3 expression. Whereas Elavl3 expression begins as soon as $24 \mathrm{~h}$ following cell birth, other markers exhibit relatively latent coexpression, including calbindin and Gad. The rapid expression of Elavl3 suggests that this marker is found in immature neurons, which later adopt more specific neuronal identities. Approximately half of PGZ cells generated postembryonically adopt a GABAergic phenotype, and previous work suggests that the other half of PGZ cells likely adopt a glutamatergic phenotype (Robles et al., 2011; Boulanger-Weill et al., 2017). Interestingly, the $\mathrm{EdU}^{+}$neuronal population generated from 4 to $5 \mathrm{dpf}$ in our phenotyping experiments included almost no $d l \times 5 /$ 6-expressing cells, which are predominantly GABAergic (Robles et al., 2011; Souza et al., 2011), suggesting that this population may be established before $4 \mathrm{dpf}$. Together, the neurogenic mechanisms governing new neuron addition in adulthood appear to guide postembryonic OT growth as well, albeit at a higher rate.

\section{Tectal growth exhibits sensory dependence after $\mathbf{1 0} \mathbf{~ d p f}$}

From 5 to $16 \mathrm{dpf}$, the tectal neuropil grows 250\% in volume; however, this growth occurs almost entirely after $10 \mathrm{dpf}$. Further- 

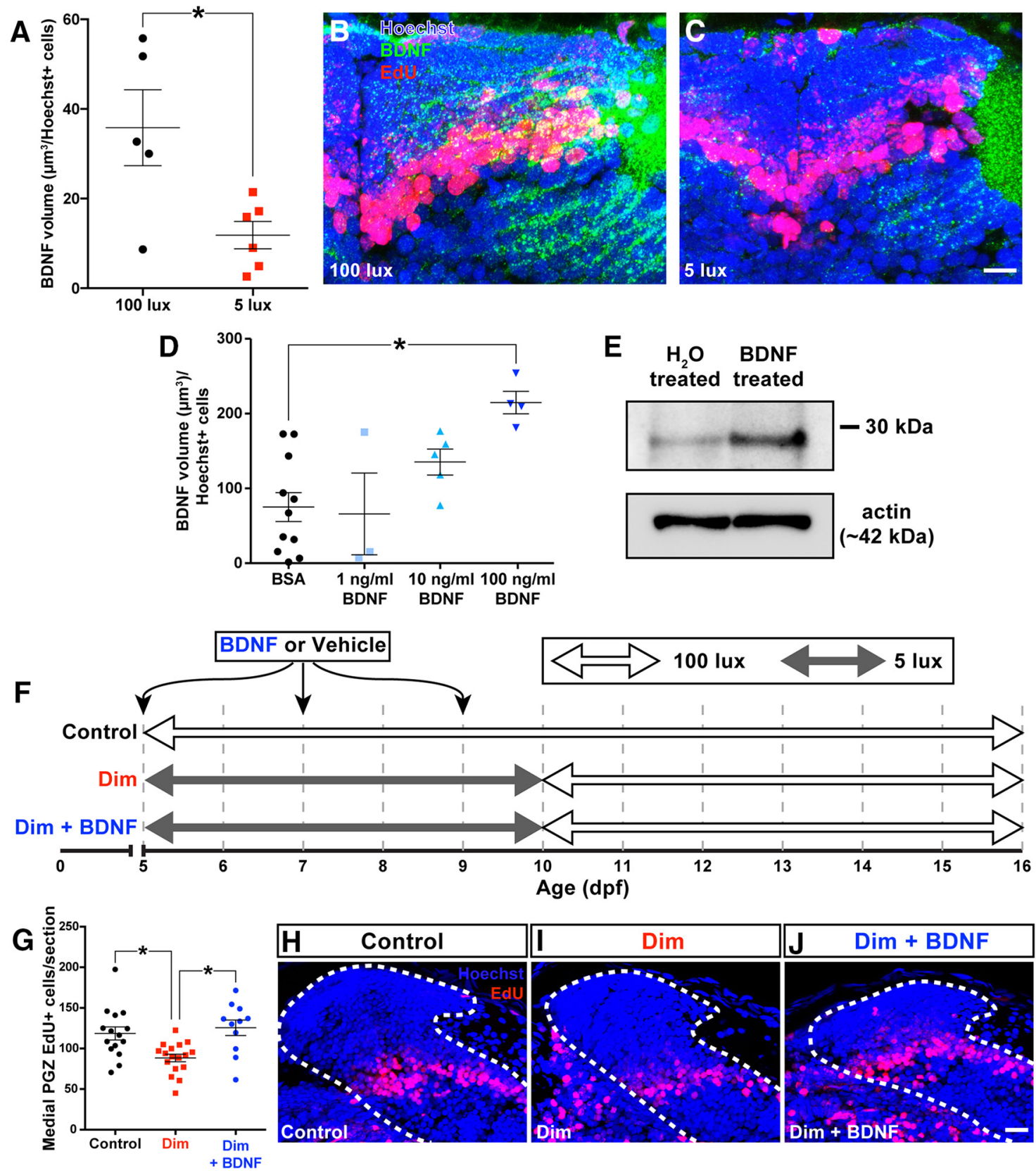

Figure 6. Rearing larvae in dim light reduces production of BDNF in the medial PGZ by $10 \mathrm{dpf}(\boldsymbol{A}-\boldsymbol{C})$. Scale bar, $15 \mu \mathrm{m}$. Injecting $5 \mathrm{dpf}$ larvae with $100 \mathrm{ng} / \mathrm{ml}$ recombinant human BDNF increased the amount of BDNF protein detected by immunohistochemistry within the medial PGZ (D) and in whole-brain lysates using a Western blot $(\boldsymbol{E})$. We supplemented larvae reared in dim light with exogenous human BDNF using three ICV injections on 5,7, and $9 \mathrm{dpf}$. Dim- and standard light-reared control larvae were injected with vehicle solutions $(\boldsymbol{F})$. Supplementing larvae reared in dim light with BDNF increased neuronal survival in the medial PGZ $(\mathbf{G}-\boldsymbol{J})$. White dotted lines indicate the boundaries of PGZ. Scale bar, $15 \mu \mathrm{m}$. Lines indicate mean \pm SEM. ${ }^{*} p<0.05$.

more, tectal neuropil growth was impaired following every tested period of dim rearing, but this underdevelopment did not manifest until after $10 \mathrm{dpf}$. The effects of dim rearing on neuronal survival, similarly, only manifest after $10 \mathrm{dpf}$. The invariance in tectal growth before $10 \mathrm{dpf}$ supports work demonstrating that several aspects of early OT development are governed largely by experience-independent mechanisms: functional characteristics of OT circuitry, including retinotopy and direction and orientation selectivity, arise in the absence of visual input by as late as 8 dpf (Niell and Smith, 2005; Lowe et al., 2013; Pietri et al., 2017). Our data suggest that a shift toward relying on visual experience to drive continued tectal growth may begin after $10 \mathrm{dpf}$, at which point visually guided behaviors critical for survival, including prey capture and predator avoidance, have developed regardless of visual input.

Visual experience protects new tectal neurons from subsequent neuronal loss

We found that restricting visual experience reduced neuronal survival in the medial PGZ. Specifically, when visual experience was restricted for the first $5 \mathrm{~d}$ after a new cohort of neurons were born, fewer neurons survived over the subsequent week, suggesting that new neurons are most vulnerable to the effects of visual experience during their first few days of life. Boulanger-Weill et al. (2017) found that new PGZ neurons exhibit rapid functional development over $4 \mathrm{~d}$ after generation, including the expression 
of neurotransmission markers, emergence of receptive fields, and correlated activity with neighboring mature neurons. When retinal input was removed (via enucleation), new neurons failed to correlate their activity with neighboring functional clusters. Whereas the authors did not track the fate of new neurons born in the absence of visual input, our results here suggest that the consequences of insufficient visual experience early in a new neuron's life is subsequent death. Boulanger-Weill et al. (2017) also found that removing visual input did not affect functional properties in preexisting PGZ neurons, and here we found that restricting visual experience had no effect on the viability of cells generated before light treatments, suggesting that preexisting neurons that have received sufficient early input become insensitive to the effects of restricted visual experience on survival.

\section{Restricting visual experience did not affect either tectal cell proliferation or the volume occupied by retinotectal arborizations}

Previous work investigating OT neurogenesis has often reported an effect of visual input on cell proliferation: removing visual input via enucleation or optic nerve crush reduces tectal proliferation (Raymond et al., 1983; Sato et al., 2017) and regeneration of retinal inputs (Stevenson and Yoon, 1978; Raymond et al., 1983) or acute dark rearing enhances tectal proliferation (Sharma and Cline, 2010). Here, we found no effect of restricting visual experience on cell proliferation and propose that this disparity may be due to the nature of our manipulation of visual experience. We restricted visual experience in larvae using dim light as this manipulation likely reflects the environmental variation in wild nesting sites of zebrafish (Engeszer et al., 2007) and avoids developmental complications associated with destructive techniques, such as the activation of regenerative mechanisms (Kizil et al., 2012), and global developmental deficits under chronic dark rearing (Bilotta, 2000). Whereas these previous findings clearly demonstrate that acute damage in visual pathways can modify tectal neurogenesis, our data suggest that the OT exhibits adaptive growth to environmental light through the selective recruitment of newborn neurons during postembryonic development.

We also found no effect of light rearing treatment on the volumetric growth of the retinotectal arborizations within the tectal neuropil from 5 to $16 \mathrm{dpf}$. By imaging the entire retinotectal arborization, we focused on the volumetric contribution of the retina to the growing tectal neuropil. Ben Fredj et al. (2010) found that, although silencing presynaptic neuronal activity in isolated retinal ganglia cells resulted in an enlarged retinotectal arborization, these same arborizations would develop normally when all retinal ganglion cells were silenced, supporting the hypothesis that retinotectal projections grow competitively among one another. We would predict that rearing larvae in dim light would affect all retinotectal projections equally, potentially explaining why this projection grew similarly in all light treatments.

\section{Visual experience protects new OT neurons via neural activity-mediated BDNF production}

We could mimic the effects of early dim rearing on PGZ neuronal survival by treating larvae with the NMDAR antagonist APV on 5 and $8 \mathrm{dpf}$. However, treating larvae with APV later than $10 \mathrm{dpf}$, or antagonizing AMPAR signaling at any point, had no effect on neuronal survival. Together, this suggests that new neurons require neural input from the retina soon after their generation to survive and mature. Consistent with a role for experiencedependent neural input in neuronal survival, Tashiro et al. (2006, 2007) found that new neurons in the adult mouse dentate gyrus require functional NMDARs during a short critical period imme- diately following their birth to avoid subsequent cell death. Furthermore, early neuronal sensitivity to NMDAR-mediated input associated with sensory experience is also observed in both retinotectal and intratectal projections in the Xenopus optic tectum (Wu et al., 1996; Pratt et al., 2016), in which initial neural activity is mediated by NMDARs, with the expression of AMPARs upregulated following neuronal maturation. Although here we found that treating larvae with the NMDAR antagonist APV mimicked the effects of early dim rearing on neuronal survival, a reduction in neuronal survival was only observed when using the highest concentration of APV tested. Thus, future studies using chronic treatments with lower concentrations of APV would be needed to confirm our findings and further validate the role of NMDAR signaling in mediating this effect.

Previous studies found that the neuroprotective effects of neural activity in vitro are likely mediated by the production of BDNF (Marini et al., 1998; Bhave et al., 1999; Balkowiec and Katz, 2002). A similar mechanism appears to regulate early neuronal addition in the retina in vivo (Martins et al., 2005). We found that both restricting visual experience and APV treatment reduced BDNF expression in PGZ. Furthermore, supplementing larvae with exogenous BDNF throughout early dim rearing prevented subsequent neuronal loss in the following days, suggesting that adaptive neurogenic growth in the zebrafish OT exhibits a similar mechanism of sensory input-mediated neuronal survival via neural activity-dependent BDNF production. Interestingly, in this model of in vivo experience-dependent neuronal survival, new neurons appear to exhibit an early period of invulnerability to cell death. Although these new neurons appear to be sensitive to visual experience during this early period, the consequences of experience on neuronal survival do not manifest until after this period of invulnerability. For example, here we found that rearing larvae in low-intensity light from 5 to $10 \mathrm{dpf}$ reduced BDNF production in the medial PGZ, but differences in cell death did not manifest until 10-16 dpf. A similar delay in the effects of sensory experience-dependent on neuronal survival has been reported in the mammalian olfactory bulb (Yamaguchi and Mori, 2005) and dentate gyrus (Tashiro et al., 2006). In support of our present data, this latter study specifically found that NMDA signaling is vital during this early period of invulnerability to ensure subsequent neuronal survival.

\section{A neurogenic model of adaptive growth in the postembryonic tectum}

We propose a model of adaptive neurogenic growth of the postembryonic OT under restricted visual experience. New cohorts of neurons are generated along the medial and lateral caudal PGZ surface appositionally. Within the first $5 \mathrm{~d}$ after generation, restricting visual experience reduces glutamatergic input from retinotectal afferents. We predict that dim light would reduce neural input to the OT based on a recent study in which reducing the intensity of visual stimuli reduced the number of activated tectal neurons (Thompson and Scott, 2016). Reduced neuronal activation results in less BDNF production in the PGZ. By $10 \mathrm{dpf}$, a proportion of new neurons receiving inadequate visual input are destined to die; however, neuronal loss does not occur until 10-16 dpf. Neuronal loss results in reduced PGZ dendritic contributions to the neuropil and, at least in part, a reduction in nonretinal neuropil volume. Functionally, the addition of new neurons to OT is hypothesized to reflect improvements in visual ability (Lee and Stevens, 2007; Cerveny et al., 2012). Accordingly, we would predict that this neuronal loss in PGZ might reflect an inability to improve visual acuity in dark 
environments. Thus, our data suggest that the visual environment becomes a major factor governing the rate of continued growth of the larval zebrafish OT via visual experience-dependent production of BDNF promoting survival of newly generated neurons.

\section{References}

Baimbridge KG, Celio MR, Rogers JH (1992) Calcium-binding proteins in the nervous system. Trends Neurosci 15:303-308. CrossRef Medline

Balkowiec A, Katz DM (2002) Cellular mechanisms regulating activitydependent release of native brain-derived neurotrophic factor from hippocampal neurons. J Neurosci 22:10399-10407. Medline

Ben Fredj N, Hammond S, Otsuna H, Chien CB, Burrone J, Meyer MP (2010) Synaptic activity and activity-dependent competition regulates axon arbor maturation, growth arrest, and territory in the retinotectal projection. J Neurosci 30:10939-10951. CrossRef Medline

Bhave SV, Ghoda L, Hoffman PL (1999) Brain-derived neurotrophic factor mediates the anti-apoptotic effect of NMDA in cerebellar granule neurons: signal transduction cascades and site of ethanol action. J Neurosci 19:3277-3286. Medline

Bilotta J (2000) Effects of abnormal lighting on the development of zebrafish visual behavior. Behav Brain Res 116:81-87. CrossRef Medline

Blakemore C, Cooper GF (1970) Development of the brain depends on the visual environment. Nature 228:477-478. CrossRef Medline

Boulanger-Weill J, Candat V, Jouary A, Romano SA, Pérez-Schuster V, Sumbre G (2017) Functional interactions between newborn and mature neurons leading to integration into established neuronal circuits. Curr Biol 27:1707-1720.e5. CrossRef Medline

Cacialli P, D'Angelo L, de Girolamo P, Avallone L, Lucini C, Pellegrini E, Castaldo L (2017) Morpho-functional features of the gonads of Danio rerio: the role of brain-derived neurotrophic factor. Anat Rec (Hoboken) 301:140-147. CrossRef Medline

Cerveny KL, Varga M, Wilson SW (2012) Continued growth and circuit building in the anamniote visual system. Dev Neurobiol 72:328-345. CrossRef Medline

Dambroise E, Simion M, Bourquard T, Bouffard S, Rizzi B, Jaszczyszyn Y, Bourge M, Affaticati P, Heuzé A, Jouralet J, Edouard J, Brown S, Thermes C, Poupon A, Reiter E, Sohm F, Bourrat F, Joly JS (2017) Postembryonic fish brain proliferation zones exhibit neuroepithelial-type gene expression profile. Stem Cells 35:1505-1518. CrossRef Medline

D’Angelo L, De Girolamo P, Lucini C, Terzibasi ET, Baumgart M, Castaldo L, Cellerino A (2014) Brain-derived neurotrophic factor: mRNA expression and protein distribution in the brain of the teleost Nothobranchius furzeri. J Comp Neurol 522:1004-1030. CrossRef Medline

De Felice E, Porreca I, Alleva E, De Girolamo P, Ambrosino C, Ciriaco E, Germanà $\mathrm{A}$, Sordino $\mathrm{P}$ (2014) Localization of BDNF expression in the developing brain of zebrafish. J Anat 224:564-574. CrossRef Medline

Deimling SJ, Halabi RR, Grover SA, Wang JH, Drysdale TA (2015) Understanding early organogenesis using a simplified in situ hybridization protocol in Xenopus. J Vis Exp 95:e51526. CrossRef Medline

Engeszer RE, Patterson LB, Rao AA, Parichy DM (2007) Zebrafish in the wild: a review of natural history and new notes from the field. Zebrafish 4:21-40. CrossRef Medline

Feliciano DM, Bordey A, Bonfanti L (2015) Noncanonical sites of adult neurogenesis in the mammalian brain. Cold Spring Harb Perspect Biol 7:a018846. CrossRef Medline

Gatta C, Altamura G, Avallone L, Castaldo L, Corteggio A, D'Angelo L, de Girolamo P, Lucini C (2016) Neurotrophins and their Trk-receptors in the cerebellum of zebrafish. J Morphol 277:725-736. CrossRef Medline

Ghanem N, Jarinova O, Amores A, Long Q, Hatch G, Park BK, Rubenstein JL, Ekker M (2003) Regulatory roles of conserved intergenic domains in vertebrate dlx bigene clusters. Genome Res 13:533-543. CrossRef Medline

Gilbert SF, Epel D (2009) Ecological developmental biology: integrating epigenetics, medicine, and evolution. Sunderland, MA: Sinauer.

Grandel H, Kaslin J, Ganz J, Wenzel I, Brand M (2006) Neural stem cells and neurogenesis in the adult zebrafish brain: origin, proliferation dynamics, migration and cell fate. Dev Biol 295:263-277. CrossRef Medline

Hensch TK (2005) Critical period mechanisms in developing visual cortex. Curr Top Dev Biol 69:215-237. CrossRef Medline

Hubel DH, Wiesel TN (1970) The period of susceptibility to the physiological effects of unilateral eye closure in kittens. J Physiol 206:419-436. CrossRef Medline

Ito $\mathrm{Y}$, Tanaka $\mathrm{H}$, Okamoto $\mathrm{H}$, Ohshima T (2010) Characterization of neural stem cells and their progeny in the adult zebrafish optic tectum. Dev Biol 342:26-38. CrossRef Medline

Ju B, Chen W, Spitsbergen JM, Lu J, Vogel P, Peters JL, Wang YD, Orr BA, Wu J, Henson HE, Jia S, Parupalli C, Taylor MR (2014) Activation of sonic hedgehog signaling in neural progenitor cells promotes glioma development in the zebrafish optic pathway. Oncogenesis 3:e96. CrossRef Medline

Kaslin J, Ganz J, Brand M (2008) Proliferation, neurogenesis and regeneration in the non-mammalian vertebrate brain. Philos Trans R Soc Lond B Biol Sci 363:101-122. CrossRef Medline

Kizil C, Kaslin J, Kroehne V, Brand M (2012) Adult neurogenesis and brain regeneration in zebrafish. Dev Neurobiol 72:429-461. CrossRef Medline

Lee S, Stevens CF (2007) General design principle for scalable neural circuits in a vertebrate retina. Proc Natl Acad Sci U S A 104:12931-12935. CrossRef Medline

Lindsey BW, Tropepe V (2006) A comparative framework for understanding the biological principles of adult neurogenesis. Prog Neurobiol 80: 281-307. CrossRef Medline

Lindsey BW, Darabie A, Tropepe V (2012) The cellular composition of neurogenic periventricular zones in the adult zebrafish forebrain. J Comp Neurol 520:2275-2316. CrossRef Medline

Lindsey BW, Di Donato S, Kaslin J, Tropepe V (2014) Sensory-specific modulation of adult neurogenesis in sensory structures is associated with the type of stem cell present in the neurogenic niche of the zebrafish brain. Eur J Neurosci 40:3591-3607. CrossRef Medline

Lowe AS, Nikolaou N, Hunter PR, Thompson ID, Meyer MP (2013) A systems-based dissection of retinal inputs to the zebrafish tectum reveals different rules for different functional classes during development. J Neurosci 33:13946-13956. CrossRef Medline

Marini AM, Rabin SJ, Lipsky RH, Mocchetti I (1998) Activity-dependent release of brain-derived neurotrophic factor underlies the neuroprotective effect of $N$-methyl-D-aspartate. J Biol Chem 273:29394-29399. CrossRef Medline

Martins RA, Silveira MS, Curado MR, Police AI, Linden R (2005) NMDA receptor activation modulates programmed cell death during early postnatal retinal development: a BDNF-dependent mechanism. J Neurochem 95:244-253. CrossRef Medline

McCurley AT, Callard GV (2008) Characterization of housekeeping genes in zebrafish: male-female differences and effects of tissue type, developmental stage and chemical treatment. BMC Mol Biol 9:102. CrossRef Medline

McDearmid JR, Drapeau P (2006) Rhythmic motor activity evoked by NMDA in the spinal zebrafish larva. J Neurophsyiol 95:401-417. CrossRef Medline

Najbauer J, Leon M (1995) Olfactory experience modulates apoptosis in the developing olfactory bulb. Brain Res 674:245-251. CrossRef Medline

Nevin LM, Robles E, Baier H, Scott EK (2010) Focusing on optic tectum circuitry through the lens of genetics. BMC Biol 8:126. CrossRef Medline

Niell CM, Smith SJ (2005) Functional imaging reveals rapid development of visual response properties in the zebrafish tectum. Neuron 45:941-951. CrossRef Medline

Pietri T, Romano SA, Pérez-Schuster V, Boulanger-Weill J, Candat V, Sumbre G (2017) The emergence of the spatial structure of tectal spontaneous activity is independent of visual inputs. Cell Rep 19:939-948. CrossRef Medline

Pratt KG, Hiramoto M, Cline HT (2016) An evolutionarily conserved mechanism for activity-dependent visual circuit development. Front Neural Circuits 10:79. CrossRef Medline

Raymond PA, Easter SS Jr (1983) Postembryonic growth of the optic tectum in goldfish: I. Location of germinal cells and numbers of neurons produced. J Neurosci 3:1077-1091. Medline

Raymond PA, Easter SS Jr, Burnham JA, Powers MK (1983) Postembryonic growth of the optic tectum in goldfish: II. Modulation of cell proliferation by retinal fiber input. J Neurosci 3:1092-1099. Medline

Robles E, Smith SJ, Baier H (2011) Characterization of genetically targeted neuron types in the zebrafish optic tectum. Front Neural Circuits 5:1. CrossRef Medline

Romano SA, Pietri T, Pérez-Schuster V, Jouary A, Haudrechy M, Sumbre G (2015) Spontaneous neuronal network dynamics reveal circuit's functional adaptations for behavior. Neuron 85:1070-1085. CrossRef Medline

Saade CJ, Alvarez-Delfin K, Fadool JM (2013) Rod photoreceptors protect from cone degeneration-induced retinal remodeling and restore visual responses in zebrafish. J Neurosci 33:1804-1814. CrossRef Medline 
Sadato N, Okada T, Honda M, Yonekura Y (2002) Critical period for crossmodal plasticity in blind humans: a functional MRI study. Neuroimage 16:389-400. CrossRef Medline

Salic A, Mitchison TJ (2008) A chemical method for fast and sensitive detection of DNA synthesis. Proc Natl Acad Sci U S A 105:2415-2420. CrossRef Medline

Sato Y, Yano H, Shimizu Y, Tanaka H, Ohshima T (2017) Optic nerve input-dependent regulation of neural stem cell proliferation in the optic tectum of adult zebrafish. Dev Nueurobiol 77:474-482. CrossRef Medline

Schmatolla E, Erdmann G (1973) Influence of retino-tectal innervation on cell proliferation and cell migration in the embryonic teleost tectum. J Embryol Exp Morphol 29:697-712. Medline

Sharma P, Cline HT (2010) Visual activity regulates neural progenitor cells in developing Xenopus CNS through musashil. Neuron 68:442-455. CrossRef Medline

Smear MC, Tao HW, Staub W, Orger MB, Gosse NJ, Liu Y, Takahashi K, Poo MM, Baier H (2007) Vesicular glutamate transport at a central synapse limits the acuity of visual perception in zebrafish. Neuron 53:65-77. CrossRef Medline

Souza BR, Romano-Silva MA, Tropepe V (2011) Dopamine D2 receptor activity modulates akt signaling and alters GABAergic neuron development and motor behavior in zebrafish larvae. J Neurosci 31:5512-5525. CrossRef Medline

Steele CJ, Bailey JA, Zatorre RJ, Penhune VB (2013) Early musical training and white-matter plasticity in the corpus callosum: evidence for a sensitive period. J Neurosci 33:1282-1290. CrossRef Medline

Stevenson JA, Yoon MG (1978) Regeneration of optic nerve fibers enhances cell proliferation in the goldfish optic tectum. Brain Res 153:345-351. CrossRef Medline

Stryker MP, Sherk H, Leventhal AG, Hirsch HV (1978) Physiological consequences for the cat's visual cortex of effectively restricting early visual experience with oriented contours. J Neurophysiol 41:896-909. CrossRef Medline

Tashiro A, Sandler VM, Toni N, Zhao C, Gage FH (2006) NMDA-receptormediated, cell-specific integration of new neurons in adult dentate gyrus. Nature 442:929-933. CrossRef Medline

Tashiro A, Makino H, Gage FH (2007) Experience-specific functional modification of the dentate gyrus through adult neurogenesis: a crit- ical period during an immature stage. J Neurosci 27:3252-3259. CrossRef Medline

Thisse B, Pflumio S, Fürthauer M, Loppin B, Heyer V, Degrave A, Woehl R, Lux A, Steffan T, Charbonnier XQ, Thisse C (2001) Expression of the zebrafish genome during embryogenesis (NIH R01 RR15402). ZFIN Direct Data Submission. Available at: http://zfin.org/ZDB-PUB-010810-1 [Accessed November 21, 2017].

Thompson AW, Scott EK (2016) Characterisation of sensitivity and orientation tuning for visually responsive ensembles in the zebrafish tectum. Sci Rep 6:34887. CrossRef Medline

Tognoli C, Rossi F, Di Cola F, Baj G, Tongiorgi E, Terova G, Saroglia M, Bernardini G, Gornati R (2010) Acute stress alters transcript expression pattern and reduces processing of proBDNF to mature BDNF in Dicentrarchus labrax. BMC Neurosci 11:4. CrossRef Medline

Urbán N, Guillemot F (2014) Neurogenesis in the embryonic and adult brain: same regulators, different roles. Front Cell Neurosci 8:396. CrossRef Medline

Walker AS, Burrone J, Meyer MP (2013) Functional imaging in the zebrafish retinotectal system using RGECO. Front Neural Circuits 7:34. CrossRef Medline

Wei L, Meaney MJ, Duman RS, Kaffman A (2011) Affiliative behavior requires juvenile, but not adult neurogenesis. J Neurosci 31:14335-14345. CrossRef Medline

Westphal RE, O'Malley DM (2013) Fusion of locomotor maneuvers, and improving sensory capabilities, give rise to the flexible homing strikes of juvenile zebrafish. Front Neural Circuits 7:108. CrossRef Medline

White EJ, Hutka SA, Williams LJ, Moreno S (2013) Learning, neural plasticity and sensitive periods: implications for language acquisition, music training and transfer across the lifespan. Front Syst Neurosci 7:90. CrossRef Medline

Wu G, Malinow R, Cline HT (1996) Maturation of a central glutamatergic synapse. Science 274:972-976. CrossRef Medline

Yamaguchi M, Mori K (2005) Critical period for sensory experience-dependent survival of newly generated granule cells in the adult mouse olfactory bulb. Proc Natl Acad Sci U S A 102:9697-9702. CrossRef Medline

Zhou X, Chen Z, Yun W, Wang H (2015) NMDA receptor activity determines neuronal fate: location or number? Rev Neurosci 26:39-47. CrossRef Medline 